\title{
1 Expression of a fungal lectin in Arabidopsis enhances plant growth and 2 resistance towards microbial pathogens and plant-parasitic nematode
}

4 Aboubakr Moradi $^{1 *}$, Mohamed El-Shetehy ${ }^{1,2}$, Jordi Gamir ${ }^{3}$, Tina Austerlitz ${ }^{4}$, Paul Dahlin ${ }^{5}$, Krzysztof

$5 \quad$ Wieczorek $^{4}$, Markus Künzler ${ }^{6 *}$ and Felix Mauch ${ }^{1}$

\section{Affiliations:}

$7 \quad{ }^{1}$ Department of Biology, University of Fribourg, Fribourg, Switzerland

$8 \quad{ }^{2}$ Botany and Microbiology Department, Faculty of Science, Tanta University, Tanta, Egypt

$9 \quad{ }^{3}$ Department Ciències Agràries i del Medi Natural (ESTCE), Universitat Jaume I, Castelló de la Plana, 10 Spain

$11{ }^{4}$ Institute of Plant Protection, Department of Crop Sciences, University of Natural Resources and Life 12 Sciences (BOKU), Vienna, Austria

$13{ }^{5}$ Agroscope, Research Division, Plant Protection, Phytopathology and Zoology in Fruit and Vegetable 14 Production, Wädenswil, Switzerland

$15{ }^{6}$ Institute of Microbiology, Department of Biology, ETH Zürich, Zürich, Switzerland

$17 *$ Correspondance

Email:aboubakr.moradi@unifr.ch

Email: markus.kuenzler@micro.biol.ethz.ch

Conflict of interest: The authors declare that they have no conflict of interest.

\section{Word count:}

Abstract: 209

Introduction: 776

Materials and Methods: 2067

Results: 1421

Discussion: 1162 


\section{Abstract}

28 Coprinopsis cinerea lectin 2 (CCL2) is a fucoside-binding lectin from the basidiomycete $C$. cinerea that

29 is toxic to the bacterivorous nematode Caenorhabditis elegans as well as animal-parasitic and

30 fungivorous nematodes. We expressed CCL2 in Arabidopsis to assess its protective potential towards

31 plant-parasitic nematodes. Our results demonstrate that expression of CCL2 enhances host resistance

32 against the cyst nematode Heterodera schachtii. Surprisingly, CCL2-expressing plants were also more

33 resistant to fungal pathogens including Botrytis cinerea, and the phytopathogenic bacterium

34 Pseudomonas syringae. In addition, CCL2 expression positively affected plant growth indicating that

35 CCL2 has the potential to improve two important agricultural parameters namely biomass production and

36 general disease resistance. The mechanism of the CCL2-mediated enhancement of plant disease

37 resistance depended on fucoside-binding by CCL2 as transgenic plants expressing a mutant version of

38 CCL2 (Y92A), compromised in fucoside-binding, exhibited wild type disease susceptibility. The

39 protective effect of CCL2 did not seem to be direct as the lectin showed no growth-inhibition towards $B$.

40 cinerea in in vitro assays. We detected, however, a significantly enhanced transcriptional induction of

41 plant defense genes in CCL2- but not CCL2-Y92A-expressing lines in response to infection with $B$.

42 cinerea compared to wild type plants. This study demonstrates a potential of fungal defense lectins in

43 plant protection beyond their use as toxins.

44 Keywords: Coprinopsis cinerea lectin 2, Heterodera schachtii, Botrytis cinerea, Pseudomonas syringae 


\section{Introduction}

47 Plants are exposed to a wide range of biotic stress caused by numerous pathogens and pests. As a consequence, plants evolved a robust multi-layered innate immune system. The first layer, pathogenassociated molecular pattern (PAMP)-triggered immunity (PTI), is activated by the perception of PAMPs such as chitin oligomers or bacterial flagellin via pattern recognition receptors at the cell surface (Jones and Dangl, 2006; Schwessinger and Zipfel, 2008). Many pathogens have evolved effectors (virulence factors) to suppress PTI (Macho and Zipfel, 2015). The second layer of plant immunity, named effectortriggered immunity (ETI), is activated via detection of pathogen effectors by plant resistance proteins (Dangl and Jones, 2001). Plant defense responses are coordinated by hormonal signaling pathways with salicylic acid (SA) and jasmonic acid (JA) playing major roles (Robert-Seilaniantz et al., 2011). A special form of induced plant disease resistance is known as systemic acquired resistance (SAR) which functions as a form of plant immunization. A local inoculation with a potential pathogen or treatment with specific chemical compounds enhances disease resistance of the whole plant against a wide range of pathogens. This is achieved by the local activation of signal transduction pathways that lead to the systemic induction of plant immune responses (Pieterse et al., 2012).

Lectins are proteins that can reversibly bind to carbohydrate epitopes on polysaccharides, glycoproteins and glycolipids. Most characterized lectins have been isolated from plants, such as the well-known examples ricin and abrin (Sharon and Lis, 2004; Vandenborre et al., 2011). Plant lectins are involved in defense-related functions and their roles in plant response to biotic and abiotic stresses have been well established (Van Damme et al., 2004; Van Holle and Van Damme, 2018). As an example, Nictaba is a lectin from tobacco whose biosynthesis is induced in response to insect herbivory or jasmonate-related compounds. It binds to N-acetylglucosamine (GlcNAc) oligomers and is toxic to phytophagous insects (Delporte et al., 2015). The Nictaba homolog in Arabidopsis is an F-box-Nictaba lectin which possesses a carbohydrate-binding activity towards Gal-GlcNAc (Stefanowicz et al., 2012). Similar to the tobacco homolog, the gene coding for F-box-Nictaba is stress-inducible (Stefanowicz et al., 2016).

71 Fungi are a valuable source of lectins with novel carbohydrate specificities. The majority of fungal lectins

72 have been discovered from fruiting bodies and sclerotia (82\%) and few from microfungi (15\%) and yeasts

73 (3\%) (Varrot et al., 2013). Fungal lectins have various applications in biomedicine, for instance as cancer cell biomarkers, diagnostic agents, mitogens, antimicrobial and antiviral agents, immunomodulators,

75 antitumor and antiproliferative agents and other therapeutic applications (Hassan et al., 2015; Singh et al., 76 2019). There are many reports describing the antimicrobial activity of fungal lectins. For example, 77 Aleuria aurantia lectin showed antifungal activity against Mucor racemosus by specifically binding to Lfucose-containing polysaccharides at the surface of fungal cell walls (Amano et al., 2012). Similarly, 
79 Gymnopilus spectabilis and Schizophyllum commune lectins inhibit the growth of Aspergillus niger 80 (Albores et al., 2014; Chumkhunthod et al., 2006). A lectin isolated from fruiting bodies of the mushroom 81 Sparassis latifolia showed antifungal and antibacterial activity (Chandrasekaran et al., 2016). Many 82 fungal lectins also show insecticidal and nematicidal activity (Künzler, 2015; Sabotic et al., 2016). For 83 example, an actinoporin-like lectin from edible mushroom Xerocomus chrysenteron is toxic to the fruit 84 fly Drosophila melanogaster and to aphids (Jaber et al., 2008; Trigueros et al., 2003). Marasmius 85 oreades agglutinin (MOA) has a $\beta$-trefoil domain with an additional cysteine-protease domain at the C86 terminus. Interestingly, both the glycolipid-binding and enzymatic activities of MOA are required for its 87 toxicity towards Caenorhabditis elegans (Wohlschlager et al., 2011). Coprinopsis cinerea lectin 2 88 (CCL2) is a $\beta$-trefoil dimeric lectin, that shows toxicity towards C. elegans and D. melanogaster (Bleuler89 Martinez et al., 2017; Schubert et al., 2012). CCL2 exerts its toxicity by binding to glycoproteins carrying 90 an $\alpha 1,3$-fucosylated N-glycan core at the surface of the C. elegans intestinal epithelium (Schubert et al., 91 2012; Stutz et al., 2015). Cytoplasmic expression of CCL2 in the fungus, Ashbya gossypii, conferred 92 resistance towards fungivorous nematodes (Tayyrov et al., 2018). Purified CCL2 inhibited larval 93 development of the animal parasitic nematode Haemonchus contortus (Heim et al., 2015).

94 There are many reports of the potential role of plant lectins in plant immunity. The role of fungal lectins 95 in the regulation of immunity is, however, poorly understood (Künzler, 2018). Similarly, their 96 biotechnological application for plant protection and disease management is largely neglected. This study 97 demonstrates that expression of CCL2 in Arabidopsis plants enhances disease resistance against the sugar 98 beet cyst nematode Heterodera schachtii, three fungal pathogens and the phytopathogenic bacterium $P$. 99 syringae. Enhanced disease resistance appears to be mediated by the carbohydrate-binding ability of 100 CCL2 as a binding-deficient mutant version of the CCL2 protein showed no protective function. 


\section{Materials and Methods}

\section{Plant growth conditions and quantification of growth phenotype}

Wild type (WT) Arabidopsis ecotype Colombia-0 (Col-0) was received from the Nottingham Arabidopsis Stock Centre (Nottingham, UK). Seeds were sown into Jiffy artificial soil (Jiffy International AS, Kristiansand, Norway). After stratification at $4{ }^{\circ} \mathrm{C}$ for 3 days, plants were transferred to growth chambers with the following condition: $22.5{ }^{\circ} \mathrm{C}$ day $/ 19^{\circ} \mathrm{C}$ night temperature and $16 \mathrm{~h}$ of light (photon flux density $100 \mu \mathrm{mmol} \mathrm{m} \mathrm{m}^{-2}$ ) with $60 \%$ relative humidity. For growth quantification rosettes of 4 four-weekold plants were harvested and carefully cleaned to remove non-plant particles. After recording the fresh weight (FW), the rosettes were incubated overnight at $80^{\circ} \mathrm{C}$ overnight to determine the dry weight (DW). The experiment was repeated three times.

\section{Construction of plant expression vectors}

Plasmids directing the expression of 3xFLAG tagged CCL2 or CCL2-Y92A under the control of the CaMV 35S promoter were constructed using the Gateway Cloning Technology (Thermo Fisher Scientific, San Jose, USA). The open reading frames of CCL2 and CCL2-Y92A were PCR-amplified from respective E. coli expression plasmids using gene-specific primers. The PCR was performed using Phusion High-Fidelity DNA Polymerase (New England Biolabs, Ipswich, USA). After agarose gel electrophoresis the PCR products were extracted from the gel with the QIAquick Gel Extraction Kit (Qiagen, Hilden, Germany) and inserted into a pENTR vector (pENTR ${ }^{\mathrm{TM}} / \mathrm{D}-\mathrm{TOPO}^{\mathrm{TM}}$ Cloning Kit, Thermo Fisher Scientific, San Jose, USA). The products were transformed into chemically competent TOP10 E. coli cells. Positive colonies were verified by colony PCR (Biometra, Goettingen, Germany) and DNA sequencing (Eurofins Genomics, Ebersberg, Germany). The entry plasmids were subsequently recombined into the binary Gateway overexpression vector pB2GW7 (Karimi et al., 2002), using LR reaction (Gateway ${ }^{\mathrm{TM}}$ LR Clonase ${ }^{\mathrm{TM}}$ II Enzyme mix, Thermo Fisher Scientific, San Jose, USA). The resulting expression plasmids containing $35 S: \because C C L 2-3 x F L A G$ or $35 S: \because C C L 2-Y 92 A-3 x F L A G$ constructs, respectively, were verified by colony PCR and transformed into Agrobacterium tumefaciens strain GV3101 by the freeze-thaw method (Schütze et al., 2009).

\section{Overexpression of CCL2 and CCL2-Y92A in Arabidopsis}

Agrobacterium-mediated transformation of Col-0 plants using the floral dip method was performed as previously described (Zhang et al., 2006). Transformed plants were selected by spraying $15 \mu \mathrm{g} / \mathrm{mL}$ of 
Glufosinate-ammonium (Basta ${ }^{\circledR}$, Bayer CropScience AG, Germany) twice within two weeks after sowing. Standard immunoblotting procedures were performed to measure the expression level of recombinant proteins in transgenic lines. Leaf tissue of 4-week-old plants was harvested and frozen in liquid nitrogen. The frozen tissue in $1.5 \mathrm{ml}$ tubes (Eppendorf, Hamburg, Germany) containing two $3 \mathrm{~mm}$ glass beads was ground with a mixer mill (Retsch ${ }^{\circledR} \mathrm{MM} 400$, Retsch Technology GmbH, Haan, Germany) adjusted at 30 $\mathrm{Hz}$ for $3 \mathrm{~min}$. Ninety $\mu \mathrm{L}$ Laemmli buffer (375 mM Tris-HCl, pH 6.8, 37\% glycerol, $0.06 \%$ bromophenol blue sodium salt, $12 \%$ sodium dodecyl sulfate, and $5 \% \quad \beta$-mercaptoethanol) was added. Tubes were incubated for $10 \mathrm{~min}$ at $95^{\circ} \mathrm{C}$ with shaking $(1400 \mathrm{rpm})$. After centrifugation $10 \mu \mathrm{L}$ of the supernatant was used for SDS-PAGE. The separated proteins were transferred to nitrocellulose membranes (SigmaAldrich) with a Mini Trans-Blot ${ }^{\circledR}$ Cell (Bio-Rad Laboratories, California, USA). As a loading control, the membranes were stained with Ponceau $\mathrm{S}$ (1\% acetic acid, $0.1 \%$ (w/v) Ponceau S) for 5 min at room temperature, washed twice with 5\% acetic acid and once with water. For immunoblotting, membranes were blocked with $3 \%$ milk in TBST buffer $(150 \mathrm{mM} \mathrm{NaCl}, 10 \mathrm{mM}$ Tris, $0.1 \%$ (v/v) Triton X-100, pH 7.6). Anti-FLAG primary antibodies (1:1000; monoclonal anti-FLAG M2-Peroxidase (HRP) clone M2, Sigma-Aldrich) were applied for $1 \mathrm{~h}$ to detect FLAG-tagged proteins. Pierce ECL Western Blotting Substrate (Thermo Fisher Scientific, USA) and horseradish peroxidase (HRP) were used for blot development. Signals were detected by ImageQuant Las 4000 (GE Healthcare Life Sciences, Marlborough, USA). From 60 transgenic plants two independent lines expressing either CCL2 or CCL2Y92A at comparable levels in the T3 generation were selected for further experiments.

\section{Construction of bacterial expression vectors}

For bacterial expression, cDNAs of CCL2 and CCL2-Y92A, respectively, were inserted between the NdeI and XhoI sites of the bacterial expression vector pET-24a containing a HIS-tag (Novagen, Madison, USA). The ligated products were transformed into TOP10 E. coli competent cells. After colony PCR and sequence verification, the purified plasmids were transformed into E. coli BL21 (DE3) for protein production (Novagen, Madison, USA).

\section{Heterologous protein expression and protein purification}

Bacterial cells were cultured in Luria Bertani (LB) broth at $37^{\circ} \mathrm{C}$ to an optical density of $\mathrm{OD}_{600}=0.8$. Protein production was induced by the addition of $0.5 \mathrm{mM}$ isopropyl $\beta$-D-1-thiogalactopyranoside (IPTG; AppliChem $\mathrm{GmbH}$, Germany). Bacteria were further incubated at $16^{\circ} \mathrm{C}$ for $18 \mathrm{~h}$. Protein extraction and purification were conducted as previously described (Schubert et al., 2012). HIS-tagged proteins were 
164

165

166

167

168

169

170

171

172

173

174

175

176

177

178

179

180

181

182

183

184

185

186

187

188

189

190

191

192

193

purified by metal-affinity chromatography using Ni-NTA resins (Qiagen, Hilden, Germany). Protein concentration was estimated by the Pierce BCA Protein Assay Kit (Thermo Fisher Scientific, San Jose, USA) and the purity of CCL2 and CCL2-Y92A was examined by SDS $\square$ PAGE.

\section{In vitro antifungal assay}

Antifungal activity of CCL2 proteins against B. cinerea strain BMM was tested in 96-well Costar cell culture plates (Corning Incorporated, Corning, USA) in a total volume of $200 \mu \mathrm{L}$. Spores of B. cinerea were diluted in 25\% PDB medium (Oxoid, Hampshire, UK) and used at a final density of $1 \times 10^{3}$ spores $\mathrm{mL}^{-1}$. Purified CCL2 proteins in $20 \mathrm{mM} \mathrm{Na}$ phosphate buffer $\mathrm{pH} 6$ were added at final concentrations of $0-1000 \mu \mathrm{g} \mathrm{mL}^{-1}$. After incubation on a shaking platform $\left(80 \mathrm{rpm} ; 20^{\circ} \mathrm{C}\right), \mathrm{OD}_{595}$ was measured using the cell imaging multi $\square$ mode plate reader Cytation ${ }^{\mathrm{TM}} 5$ (Biotek, Winooski, USA). The absorbance reads were analyzed with Gen5 Image+ Software (Version 3.03.14, BioTek, Winooski, USA). Growth curves were generated by GraphPad Prism version 8.0.2 (GraphPad Software, Inc., La Jolla, USA). Experiments were repeated 3-times.

\section{Heterodera schachtii infection assay}

H. schachtii infection assays were performed according to (Bohlmann and Wieczorek, 2015). Transgenic seeds were surface-sterilized (Lindsey et al., 2017), and grown on selective Murashige Skoog medium (MS) contained $3 \%$ sucrose and $10 \mathrm{mg} \mathrm{L}^{-1}$ glufosinate-ammonium. Col-0 was grown on plates without glufosinate-ammonium. After five days, healthy seedlings were transferred to plates containing a modified 0.2 concentrated Knop medium supplemented with $2 \%$ sucrose (Sijmons et al., 1991). Six plates per line with eight plants per plate were incubated in the growth chamber for seven days. Cysts of $H$. schachtii were collected from in vitro stock cultures. Hatching of $2^{\text {nd }}$ stage juveniles (J2s) was stimulated by soaking cysts in $3 \mathrm{mM} \mathrm{ZnCl}_{2}$. Prior to inoculation, the $\mathrm{J} 2 \mathrm{~s}$ were sterilized, and total root length was estimated according to $\mathrm{Ju} \square$ rgensen (2001). For infection assays, plants were inoculated with 30 freshly hatched J2s per plant, left in the dark overnight and then transferred into a growth chamber. The nematode infection was assessed $14 \mathrm{dpi}$. The total numbers of females per root $\mathrm{cm}$ were calculated and the experiment was repeated three times.

\section{Disease resistance tests}


Two-independent CCL2 overexpressing lines or CCL2-Y92A overexpressing lines and WT were grown under the described conditions. After four weeks, four leaves per plant were inoculated with $6 \mu \mathrm{L}$ droplets of a spore suspension $\left(5 \times 10^{4}\right.$ spores $\left.\mathrm{mL}^{-1}\right)$ of $B$. cinerea. Plants were covered with a transparent plastic dome to keep high humidity and incubated in the dark. At 3 dpi, the lesion size was measured by Vernier caliper (MarCal $16 \mathrm{ER}$, Mahr $\mathrm{GmbH}$, Germany). Twenty plants per line were tested, and three independent biological replicates were performed. Fungal hyphae and dead plant tissues were stained in a solution of ethanolic lactophenol Trypan Blue (Hael-Conrad et al., 2015). The samples were analyzed using a Leica DMR microscope with bright-field settings. Colletotrichum higginsianum was grown on oatmeal agar (Condalab S.A., Madrid, Spain) for 7 days at $22^{\circ} \mathrm{C}$. Four leaves of five-week-old Arabidopsis plants were inoculated with $10 \mu \mathrm{L}$ droplets of $2 \times 10^{6}$ conidia $\mathrm{mL}^{-1}$ suspended in $25 \%$ PDB. Droplets of $25 \%$ PDB were used as a mock treatment. Plants were covered with a plastic dome to keep humidity and incubated in the growth chamber. Lesions were measured 10 dpi with a digital Vernier caliper (MarCal 16 ER, Mahr GmbH, Germany). Ten plants per line were tested and three independent biological replicates were performed. Plectosphaerella cucumerina was grown on CM0139 Potato Dextrose Agar plates (Oxoid, Hampshire, UK) at $25^{\circ} \mathrm{C}$. Four leaves of four-week-old Arabidopsis plants were infected with $10 \mu \mathrm{L}$ droplets of $5 \times 10^{6}$ spores $\mathrm{mL}^{-1}$ suspended in $25 \%$ PDB. The conditions of inoculation were as described for C. higginsianum. Lesion size was measured at 5 dpi. Ten plants per line were tested, and three independent biological replicates were performed. Pseudomonas syringae pv. tomato (Pst) DC3000 was cultured overnight at $28^{\circ} \mathrm{C}$ with shaking $(180 \mathrm{rpm})$ in liquid LB medium (supplied with $50 \mathrm{mg} \mathrm{L}^{-1}$ rifampicin). Bacterial cells were centrifuged at $3000 \mathrm{rpm}$ for $10 \mathrm{~min}$, and the pellet was diluted in $10 \mathrm{mM} \mathrm{MgCl} 2$. For basal disease resistance assay, the leaves of four-week-old plants were syringe-infiltrated with bacterial suspension of Pst DC3000 $\left(10^{5} \mathrm{CFU} \mathrm{mL}^{-1}\right)$. Infiltrated leaves were harvested 72 hpi for quantification by qPCR of the $O p r F$ gene (Genebank 878442) as a marker of bacterial growth.

\section{Quantification of fungal and bacterial biomass}

The fungal biomass was quantified according to Gachon and Saindrenan (2004), with minor modifications. Ten leaf discs were harvested from inoculated leaves and immediately frozen in liquid $\mathrm{N}_{2}$. For each line, three independent biological replicates were performed. Total DNA was isolated using Plant DNA mini Kit (Peqlab/VWR, Darmstadt, Germany). To quantify fungal or bacterial DNA content, the qPCR mixtures were prepared with $12.5 \mu \mathrm{L}$ of SYBR Green mix (Bioline, London, UK), $10 \mu \mathrm{L}$ of DNA (final amount $100 \mathrm{ng}$ ), and $0.75 \mu \mathrm{L}$ of forward and reverse primers (10 $\mu \mathrm{M}$; Table $\mathrm{S} 1$ ). The final volume was $25 \mu \mathrm{L}$. The qPCR was conducted with a MIC qPCR machine (Bio Molecular Systems, 
Australia) using the following conditions: $10 \mathrm{~min}$ at $95^{\circ} \mathrm{C}$ initial denaturation and 40 cycles $\left(95^{\circ} \mathrm{C}\right.$ for $15 \mathrm{~s}$, $60^{\circ} \mathrm{C}$ for $1 \mathrm{~min}$ and $72^{\circ} \mathrm{C}$ for $30 \mathrm{~s}$ ). Specificity of amplification was analyzed by melting point analysis. The level of the fungal Cutinase A gene (Genebank Z69264) or the bacterial OprF gene (Genebank 878442) were normalized against the $\exp G$ gene (AT4G26410) of Arabidopsis (Czechowski et al., 2005). The $2^{(-\Delta \Delta \mathrm{Ct})}$ method was used to analyze the results (Rao et al., 2013).

\section{Systemic acquired resistance (SAR)}

Three leaves of four-week-old Col-0 plants were infiltrated with either $500 \mu \mathrm{g} \mathrm{mL}^{-1}$ of purified CCL2 or purified CCL2-Y92A in $10 \mathrm{mM} \mathrm{MgCl}_{2}$.Infiltration with Pst DC3000 at $10^{6} \mathrm{CFU} \mathrm{mL}^{-1}$ in $10 \mathrm{mM} \mathrm{MgCl}_{2}$ served as positive control. Infiltration with $10 \mathrm{mM} \mathrm{MgCl}_{2}$ served as negative control. After $48 \mathrm{~h}$, three distal leaves were inoculated with Pst DC3000 $\left(10^{5} \mathrm{CFU} \mathrm{mL} \mathrm{m}^{-1}\right)$. Ten leaf discs were harvested from the distal leaves 3dpi with a cork borer (discs from different plant leaves) and used for DNA extraction. The level of the bacterial oprF gene (Genbank 878442) was analyzed by qPCR. For transcript levels of SAR defense-related genes after the primary treatments, local leaves were sampled 2 days post treatment for RNA extraction, cDNA synthesis and qPCR analyses.

\section{Transcript levels of defense-related genes}

Transcript levels of defense-related genes in response to B. cinerea or Pst were analyzed by qPCR. Leaves were ground in liquid $\mathrm{N}_{2}$, and total RNA was extracted with the Spectrum ${ }^{\mathrm{TM}}$ Plant Total RNA Kit (Sigma Aldrich, Saint Louis, USA). The isolated RNA was treated with deoxyribonuclease I enzyme (Sigma Aldrich) to remove remaining DNA. Two micrograms of purified RNA were used for reverse transcription reactions with the Omniscript Reverse Transcription Kit (Qiagen, Hilden, Germany). The qPCR mixture contained $7.5 \mu \mathrm{L}$ of SYBR Green (Bioline, London, $\mathrm{UK}$ ), $5 \mu \mathrm{L}$ of cDNA (corresponding to $100 \mathrm{ng}$ RNA), and $0.5 \mu \mathrm{L}$ of $10 \mu \mathrm{M}$ forward and reverse primers (Table S1). The final volume was completed with DEPC water to $15 \mu \mathrm{L}$. The qPCR was done as follows: $10 \mathrm{~min}$ at $95^{\circ} \mathrm{C}$ initial denaturation and 40 cycles $\left(95^{\circ} \mathrm{C}\right.$ for $15 \mathrm{~s}, 60^{\circ} \mathrm{C}$ for $1 \mathrm{~min}$ and $72^{\circ} \mathrm{C}$ for $\left.30 \mathrm{~s}\right)$. Runs were performed on a MIC qPCR machine (Bio Molecular Systems, Australia). Transcript levels were normalized against the $\exp G$ gene (AT4G26410). The analysis was accomplished based on cycle threshold method (2 ${ }^{(-\Delta \Delta \mathrm{Ct})}$; Rao et al., 2013). Three biological replicates were performed for each sample.

\section{Statistical analysis}


258 Statistical analysis was carried out using GraphPad Prism version 8.0.2 (GraphPad Software, Inc., La 259 Jolla, USA). One/two-way ANOVA analysis was conducted to identify significant differences among 260 treatments relative to the control. Tukey or Dunnett tests were used for multiple comparisons between the

261 TG lines and control. Asterisks indicate statistically significant differences $(* * * \mathrm{P} \leq 0.001$, **P $\leq 0.01, * \mathrm{P}$

$262 \leq 0.05$ ) whereas ns (not significant) indicates $\mathrm{P}>0.05$. The letters a and $\mathrm{b}$ signify a between-group

263 difference at the $\mathrm{P} \leq 0.05$ level. 
Results

\section{Expression of CCL2 in Arabidopsis boosts plant growth}

266

FLAG-tagged CCL2 and a mutated FLAG-tagged CCL2-Y92A version compromised in fucoside-binding were expressed in Arabidopsis (accession Col-0) under the control of the CaMV-35S promoter using the constructs 35S::CCL2-3xFLAG and 35S::CCL2-Y92A-3xFLAG, respectively. Transgenic plants were analyzed by qPCR and immunoblotting to select lines with a comparable expression level of CCL2 or CCL-Y92A, respectively (Fig. 1A and B). The transgenic lines grew bigger than WT plants (Fig. 1C). Quantification of rosettes of four-week-old plants indicated that fresh weight (FW) and dry weight (DW) were significantly higher in transgenic plants (Fig. 1D, and E). In CCL2 lines FW and DW of rosettes were $100 \%$ and $95 \%$ higher than in WT plants, respectively. The differences of FW and DW for CCL2Y92A lines were not statistically significant compared to the WT plants.

\section{CCL2 enhances disease resistance against the plant-parasitic nematode Heterodera schachtii}

Based on the previous in vitro evidence for nematicidal activity, CCL2 and CCL2-Y92A-expressing Arabidopsis lines were tested with the agronomically important sugar beet cyst nematode $H$. schachtii. Transgenic lines and WT plants were inoculated with $\mathrm{J} 2$ juveniles and the progression of nematode infection was evaluated in roots. The results indicated a protective effect of CCL2. The number of $H$. schachtii females per $\mathrm{cm}$ of root was significantly reduced by $35 \%$ in CCL2 lines compared to WT plants (Figure 2). In contrast, CCL2-Y92A-expressing lines showed similar susceptibility as WT plants. Our results indicate that CCL2 expression partially protected Arabidopsis roots from parasitism by $H$. schachtii and that the protective effect was dependent on carbohydrate-binding activity of CCL2.

\section{CCL2 enhances resistance of Arabidopsis against fungal pathogens}

In order to test whether the protective effect of CCL2 was specific for nematodes or more general, the transgenic CCL2 lines and WT plants were inoculated with droplets of a suspension of conidiospores of the fungal pathogen B. cinerea. B. cinerea, known as grey mold, is a necrotrophic plant pathogen that can infect more than 200 plant species, causing losses of agricultural products both pre $\square$ and post $\square$ harvest (Dean et al., 2012). The lesion size caused by the fungal infection was analyzed at 3 dpi (day postinoculation). The pathogen successfully colonized WT and CCL2-Y92A-expressing plants as indicated by the formation of large necrotic lesions spreading from the inoculation site. In contrast, in the two CCL2expressing lines such lesions were significantly smaller and surrounded by a lighter colored halo (Fig. 
3A). Trypan Blue staining revealed the growth of fungal hyphae within the infected leaves. In WT and CCL-Y92A-expressing plants, fungal hyphae spread through the leaves whereas the colonization of leaves by the fungus was impaired in CCL2-expressing plants (Fig. 3B). Quantitative analysis showed that the lesion size in the CCL2 plants, including the lighter colored halo, was reduced to 54\% compared to WT. No significant difference was detected between CCL2-Y92A lines and WT plants (Fig. 3C). Quantification of fungal biomass based on qPCR analysis of fungal DNA present in inoculated plants confirmed the results of the macro- and microscopic analysis (Fig. 3D). At 2 dpi, the B. cinerea biomass was significantly higher in WT and CCL2-Y92A plants compared to CCL2 plants. These results indicated that expression of CCL2 inhibited colonization of the plant by the fungus in a carbohydrate-bindingdependent manner. In order to test the specificity of the antifungal effect of CCL2, the Arabidopsis CCL2 lines, CCL2-Y92A lines and WT plants were challenged with the fungal pathogens Colletotrichum higginsianum or Plectosphaerella cucumerina. C. higginsianum is a hemibiotrophic pathogen that globally causes disease in many economically important crops (Yan et al., 2018). Likewise, $P$. cucumerina is a necrotrophic pathogen that causes diseases in crops worldwide (Sanchez-Vallet et al., 2010). Plant leaves were inoculated with droplets of $C$. higginsianum spore suspensions. CCL2 lines showed at 10 dpi a significant reduction of lesion size of 60\% (L1) and 59\% (L2) compared to WT plants (Fig. 3E). Similarly, after inoculation with spores of P. cucumerina, the lesions of the CCL2 lines after 5 dpi were 39\% (L1) and 36\% (L2) smaller than in WT plants (Fig. 3F). Plants expressing CCL-Y92A showed WT-like disease resistance to both fungi. Taken together, the results demonstrate that expression of CCL2 partially protected plants against a variety of fungal pathogens, including necrotrophs ( $B$. cinerea and $P$. cucumerina) and hemibiotrophs ( $C$. higginsianum). The protective effect depended on the ability of CCL2 to bind carbohydrates.

\section{CCL2 enhances transcript accumulation of plant defense genes upon pathogen inoculation}

In order to assess whether the fungal growth inhibition by the CCL2 lectin is direct, an in vitro assay for antifungal activity towards $B$. cinerea was conducted. The purified His-tagged CCL2 proteins (CCL2 and CCL2-Y92A; Supplementary Fig. S1) were applied to fungal spores in liquid medium and spore germination and hyphal growth were assessed. No inhibition of fungal growth was detected even at a concentration of $1 \mathrm{mg} \mathrm{mL} \mathrm{m}^{-1}$ of purified protein (Supplementary Fig. S2). Based on these results, we reasoned that CCL2 might have an indirect effect on plant protection via the activation of plant immune responses. The transcript levels of Arabidopsis defense genes in WT plants and transgenic lines infection were assessed by qPCR (Fig. 4A-C). Analyzed Arabidopsis defense genes included methyl JA-inducible marker genes (OBP2, AT1G07640), PLANT DEFENSIN (PDF1.2: AT5G44420) and SA-inducible PATHOGENESIS-RELATED PROTEIN-1 (PR-1: AT2G14610). No significant differences in transcript 
levels between WT and transgenic lines were observed at 0 dpi indicating that CCL2 expression did not directly trigger defense gene expression. However, transcript levels of all three genes were enhanced at 1 dpi in CCL2 lines compared to WT and CCL2-Y92A lines. Induction of $O B P 2$ transcript levels was enhanced 3.5-fold, PDF1.2 transcripts 12-fold and PR-1 transcripts 2.5-fold compared to WT at 1 dpi indicating a priming effect of CCL2 on pathogen-induced expression of these genes. The respective transcript levels were not significantly different between WT and CCL2-Y92A lines. These results suggested that the protective effect of CCL2-expression in Arabidopsis towards fungal pathogens might be achieved by boosting the immune responses of the host plant upon pathogen inoculation.

\section{Resistance against Pseudomonas syringae is enhanced in CCL2 lines}

Based on the increased resistance of the CCL2 lines against a variety of fungal plant pathogens, we were interested in assessing the resistance of plants against the bacterial plant pathogen Pseudomonas syringae pv. tomato (Pst), a hemibiotrophic pathogen that can infect many plant species (Glazebrook, 2005). WT

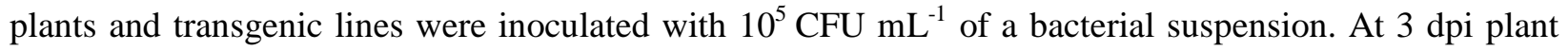
tissues were analyzed by qPCR to quantify bacterial DNA based on the bacterial OprF gene (Ross and Somssich, 2016). The bacterial biomass based on $O p r F$ content was significantly reduced by $73 \%$ and 57\% in the CCL2 lines 1 and 2, respectively, compared to WT (Fig. 5). The difference between the CCL2-Y92A lines and WT was not significant. The results indicated that the expression of CCL2 enhanced the resistance towards $P$. syringae. Similar to the results with fungal pathogens, the protective effect depended on the carbohydrate-binding activity of CCL2 as the mutant version CCL2-Y92A failed to protect plants against $P$. syringae.

\section{Exogenous application of purified CCL2 protein confers systemic acquired resistance (SAR)}

To further support the immune-activating properties of CCL2, the potential of exogenously applied CCL2 for activation of defense gene expression and induction of SAR was analyzed. Purified CCL2 protein $\left(500 \mu \mathrm{g} \mathrm{mL}^{-1}\right)$ was locally infiltrated into leaves of WT plants and disease resistance towards Pst DC3000 was analyzed in untreated distal leaves. Treatment of local leaves with CCL2 led to an induction of SAR against Pst DC3000 in challenge-inoculated systemic leaves comparable to inoculation of local leaves with Pst (Fig. 6A). In contrast, treatment with CCL2-Y92A failed to induce SAR as no significant difference compared to mock treatment was observed. The results suggested that exogenously applied CCL2 protein induced SAR against $P s t$ in a carbohydrate-binding dependent manner. To test the potential of CCL2 for direct activation of defense gene expression, WT plants were infiltrated with purified CCL2 protein $\left(500 \mu \mathrm{g} \mathrm{mL}^{-1}\right)$ and transcript levels of a number of defense-related genes were analyzed 48 hours 
362 after treatment: GLII (AT1G80460) encoding a glycerol kinase, GLYCEROL-3-PHOSPHATE (G3P)

363 SYNTHESIS GENE GLY1 (AT2G40690), PR-1 (AT2G14610), RESPIRATORY BURST OXIDASE

364 HOMOLOGS D and F (RBOHD: AT5G47910 and RBOHDF: AT1G64060). Similar to treatment with

365 the positive SAR control Pst, treatment with purified CCL2 protein resulted in significant

366 increases compared to mock treatment in transcript abundance of all tested genes (Fig. 6B-F).

367 CCL2-treated local leaves of WT plants showed a 39-fold, 13-fold, 13-fold, 19-fold and 8-fold

368 increase in transcript levels of $G L I 1, G L Y 1, P R-1, R B O H D$ or $R B O H F$, respectively, compared

369 to mock-inoculated plants. 


\section{Discussion}

372 The aim of our research was to test transgenic plants expressing the nematicidal CCL2 lectin of $C$.

373 cinerea for enhanced disease resistance towards plant-parasitic nematodes. To this end, CCL2 or the

374 binding-compromised mutated version CCL2-Y92A were constitutively expressed in Arabidopsis plants.

375 Surprisingly, transgenic CCL2 lines showed multiple phenotypes. They were not only more resistant than

376 WT against the sugar beet cyst nematode $H$. schachtii but also showed improved disease resistance 377 towards fungal and bacterial pathogens. In addition, CCL2 expression had a positive effect on plant 378 growth. The multiple phenotypes of CCL2 plants depended on the previously demonstrated carbohydrate379 binding activity of CCL2 (Bleuler-Martinez et al., 2017; Schubert et al., 2012) as expression of CCL2Y92A, a mutated version compromized in carbohydrate binding, did not cause detectable differences compared to WT plants. Unless CCL2 has additional, as of yet undiscovered carbohydrate-binding activities, the observed disease resistance related phenotypes must be the result of binding of CCL2 to $\alpha 1,3$-fucosylated $\mathrm{N}$-glycan cores.

Entomotoxic and nematotoxic activity of fungal lectins has been widely studied (Bleuler-Martinez et al., 2011; Künzler, 2015; Sabotic et al., 2016). Similarly, in vitro antibacterial and antifungal activity of fungal lectins against pathogens have been described (Albores et al., 2014; Amano et al., 2012; Breitenbach Barroso Coelho et al., 2018; Chandrasekaran et al., 2016; Singh et al., 2014). Transgenic plants expressing plant lectins showed enhanced resistance to phytopathogens and pests (Burrows et al., 1998; Ripoll et al., 2003; Stefanowicz et al., 2016; Van Holle et al., 2016). However, to date no lectins of fungal origin have been expressed in plants for disease protection. CCL2-overexpressing Arabidopsis plants showed significantly reduced susceptibility to the cyst nematode $H$. schachtii. The protective effect of CCL2 is most probably mediated by its carbohydrate-binding activity as the CCL2-Y92A lines do not show improved resistance against nematodes. $H$. schachtii is an obligate biotroph taking up the nutrients only after induction of feeding sites within the host root tissue. Hence, it was not possible to directly test in vitro toxic effects of CCL2 on parasite development. It remains, therefore, an open question whether the protective effect of CCL2 is direct via its nematicidal activity and/or indirect via primed induction of plant defenses as shown for other priming-active compounds known to enhance resistance towards e.g. root-knot nematodes (Cohen et al., 2016; Oka et al., 1999).

CCL2 lines were compared to WT and CCL2-Y92A lines more resistant to three fungal pathogens. The 400 failure of CCL2-Y92A to protect plants from infection indicates that the carbohydrate-binding activity of 401 CCL2 is essential for the observed protection. CCL2 did not have a toxic effect on the in vitro growth of 402 B. cinerea. Hence, CCL2 is unlikely to protect plants via direct antifungal activity. As an alternative, we 403 tested whether CCL2 possibly protects plants indirectly via activation of plant defense responses. 
Transgenically expressed CCL2 had no direct effect on the constitutive expression of defense genes. However, in response to $B$. cinerea CCL2 plants showed a significantly enhanced accumulation of transcripts of JA-regulated $O B P 2$ and $P D F 1.2$ as well as SA-regulated $P R-1$ genes compared to WT and CCL2-Y92A lines. The CCL2 lines reacted more strongly in terms of defense gene expression to inoculation with $B$. cinerea. Boosted activation of defense gene expression in response to pathogens, also called priming, has been demonstrated to enhance general disease resistance (Conrath et al., 2006; Mauch-Mani et al., 2017). It is, therefore, likely that the CCL2-mediated defense priming contributes to the enhanced protection of CCL2-expressing lines against fungal pathogens. Priming typically enhances disease resistance against many different pathogens. In line with this, CCL2 lines were also significantly more resistant to the bacterial pathogen Pst.

Local treatment with purified CCL2 enhanced the disease resistance towards Pst in systemic leaves comparable to primary inoculation with the known SAR inducer Pst. In contrast, treatment with purified CCL2-Y92A had no effect on disease resistance in systemic leaves. Hence, CCL2 activated SAR signaling pathways dependent on its carbohydrate-binding activity. Transcript levels of SAR-related genes were significantly enhanced in local leaves of CCL2-infiltrated WT plants compared to mocktreated plants indicating that CCL2 functions similarly to other defense activating compounds (Tripathi et al., 2019). Transgenically expressed CCL2 did not directly affect defense gene expression as the transgenic CCL2 lines showed WT transcript levels in the absence of a pathogen. In contrast, treatment of plants with purified CCL2 caused enhanced transcript accumulation of defense genes. This contradiction is likely the result of the different concentrations of CCL2 present in the transgenic lines and in plants treated with purified CCL2. Many priming active compounds are known to directly induce immune responses depending on their concentration (Conrath et al., 2006; Mauch-Mani et al., 2017). At lower concentrations they still can protect plants from infection without directly affecting defense gene expression by sensitizing the induction of defense responses upon pathogen attack. The positive effect of CCL2 expression on plant growth was an unexpected finding as plants manipulated for enhanced disease resistance often suffer from fitness costs (Bowling et al., 1994; Mauch et al., 2001). However, priming effects at low concentrations are normally not linked with a growth penalty (Conrath et al., 2006; MauchMani et al., 2017). The positive effect of CCL2 on plant growth also depends on the carbohydrate-binding activity.

Similar to previous findings showing nematicidal activity of CCL2 (Bleuler-Martinez et al., 2017; Schubert et al., 2012), our results confirm the importance of the binding of CCL2 to $\alpha 1,3$-fucosylated Nglycans for its immune-stimulating function as the binding-deficient mutant CCL2-Y92A was not able to protect plants against plant-parasitic nematodes and microbial pathogens. We speculate that CCL2 enhances plant immunity via binding to plant glycoproteins or other glycosylated compounds that are 
438 involved in regulation of immunity. Interestingely, a recent study indicated that $\alpha 1,3$-fucosylated $\mathrm{N}$ -

439 glycans play an essential role in plant immunity (Zhang et al., 2019). Mutations in a gene involved in the

440 biosynthesis of GDP-L-fucose (SCORD6/MURI) negatively affected PTI and ETI, including

441 glycosylation of immune receptors. In addition, compromised defenses were also observed in mutants of

442 several fucosyltransferases with specific substrates (O-glycan, N-glycan or DELLA transcriptional

443 repressors; Zhang et al., 2019). These results hinted to a so far unknown plant immunity-related role of L-

444 fucose biosynthesis and fucosylation. Biochemical approaches will be needed to identify the plant targets

445 of CCL2.

446 In summary, overexpression of CCL2 in Arabidopsis improved plant growth and general disease

447 resistance towards the cyst nematode $H$. schachtii and various plant pathogens. Protection against $H$.

448 schachtii is likely based on the direct nematotoxic effect of CCL2. CCL2 did not show direct toxicity

449 towards fungi but primed the expression of JA/SA-related defense genes that are important for plant

450 immunity against microbial pathogens. Thus, CCL2 is postulated to induce resistance against microbial

451 pathogens by binding to fucosylated compounds with a role in plant immunity. In agreement with such a

452 model, the mutant version of CCL2 with abolished carbohydrate-binding lost its protective function.

453 Thus, the fungal lectin CCL2 does not only function as a nematotoxin but has additional roles as a

454 positive regulator of plant immunity. 


\section{Supporting information}

456 Table S1 Sequences of primers for qPCR. F: Forward primer. R: Reverse primer.

457 Figure S1 CCL2 expression in E. coli and purification.

458 Figure S2 In vitro antimicrobial assay of bacterially produced CCL2 and CCL2-Y92A against B. cinerea.

\section{Acknowledgments}

461 AM was supported by a Swiss Government Excellence Scholarship for Foreign Scholars (Swiss State 462 Secretariat for Education, Research, and Innovation). FM was supported by the Swiss National Science 463 Foundation (grant no. 31003A_129696). MK is supported by the Swiss National Science Foundation 464 (grant no. 31003A_173097).

\section{Authors contributions}

467 AM: production of CCL2 expressing transgenic Arabidopsis plants, disease resistance tests with $B$. 468 cinerea and C. higginsianum; heterologous expression of CCL2 in E. coli; antifungal assays; planning 469 projects, analyzing data and writing of manuscript; ME: disease resistance against Pst and SAR 470 experiments; JG: disease resistance tests against $P$. cucumerina; TA and KW: $H$. schachtii infection 471 assays; PD: writing of manuscript; MK: provided CCL2 and CCL2-Y92A cDNAs; planning projects and 472 writing of manuscript; FM: supervising, planning projects and writing of manuscript.

\section{Availability of data and materials}

475 The raw data of the presented results of this study are available on request to the corresponding author.

477 Accession numbers

478 CCL2 (GenBank ACD88750; oprF (Genbank: 878442); cutinase A (Genbank Z69264); PDF 1.2 479 (AT5G44420); PR-1 (AT2G14610); OBP2 (AT1G07640); GLI1 (AT1G80460); GLY1 (AT2G40690); RBOHD (AT5G47910); RBOHF (AT1G64060); $\exp G$ (AT4G26410). 


\section{References}

Albores S, Mora P, Bustamante MJ, Cerdeiras MP, Franco Fraguas L. 2014. Purification and applications of a lectin from the mushroom Gymnopilus spectabilis. Appl Biochem Biotechnol 172, 20812090.

Amano K, Katayama H, Saito A, Ando A, Nagata Y. 2012. Aleuria aurantia lectin exhibits antifungal activity against Mucor racemosus. Biosci Biotechnol Biochem 76, 967-970. higher fungi against predators and parasites. Mol Ecol 20, 3056-3070.

Künzler M. 2017. Dimerization of the fungal defense lectin CCL2 is essential for its toxicity against nematodes. Glycobiology 27, 486-500.

Bohlmann H, Wieczorek K. 2015. Infection assay of cyst nematodes on arabidopsis roots. Bio Protoc 5, 496 e1596.

497 Bowling SA, Guo A, Cao H, Gordon AS, Klessig DF, Dong X. 1994. A mutation in Arabidopsis that leads to constitutive expression of systemic acquired resistance. Plant Cell 6, 1845-1857. 2018. Lectins as antimicrobial agents. J Appl Microbiol 125, 1238-1252.

502 Burrows PR, Barker AD, Newell CA, Hamilton W. 1998. Plant $\square$ derived enzyme inhibitors and lectins 503 for resistance against plant $\square$ parasitic nematodes in transgenic crops. Pesticide Sci 52, 176-183.

504 Chandrasekaran G, Lee YC, Park H, Wu Y, Shin HJ. 2016. Antibacterial and antifungal activities of

505 lectin extracted from fruiting bodies of the Korean cauliflower medicinal mushroom, Sparassis latifolia 506 (Agaricomycetes). Int J Med Mushrooms 18, 291-299.

507 Chumkhunthod P, Rodtong S, Lambert SJ, Fordham-Skelton AP, Rizkallah PJ, Wilkinson MC, 508 Reynolds CD. 2006. Purification and characterization of an N-acetyl-D-galactosamine-specific lectin 509 from the edible mushroom Schizophyllum commune. Biochim Biophys Acta 1760, 326-332.

510 Cohen Y, Vaknin M, Mauch-Mani B. 2016. BABA-induced resistance: milestones along a 55-year 511 journey. Phytoparasitica 44, 513-538.

512 Conrath U, Beckers GJ, Flors V, Garcia-Agustin P, Jakab G, Mauch F, Newman MA, Pieterse CM, 513 Poinssot B, Pozo MJ, Pugin A, Schaffrath U, Ton J, Wendehenne D, Zimmerli L, Mauch-Mani B. 514 2006. Priming: getting ready for battle. Mol Plant Microbe Interact 19, 1062-1071. 
515 Czechowski T, Stitt M, Altmann T, Udvardi MK, Scheible WR. 2005. Genome-wide identification

516 and testing of superior reference genes for transcript normalization in Arabidopsis. Plant Physiol 139, 5-

51717.

518 Dangl JL, Jones JD. 2001. Plant pathogens and integrated defence responses to infection. Nature 411,

$519 \quad 826-833$.

520 Dean R, Van Kan JA, Pretorius ZA, Hammond-Kosack KE, Di Pietro A, Spanu PD, Rudd JJ,

521 Dickman M, Kahmann R, Ellis J, Foster GD. 2012. The Top 10 fungal pathogens in molecular plant 522 pathology. Mol Plant Pathol 13, 414-430.

523 Delporte A, Van Holle S, Lannoo N, Van Damme EJ. 2015. The tobacco lectin, prototype of the family 524 of Nictaba-related proteins. Curr Protein Pept Sci 16, 5-16.

525 Gachon C, Saindrenan P. 2004. Real-time PCR monitoring of fungal development in Arabidopsis 526 thaliana infected by Alternaria brassicicola and Botrytis cinerea. Plant Physiol Biochem 42, 367-371.

527 Glazebrook J. 2005. Contrasting mechanisms of defense against biotrophic and necrotrophic pathogens. 528 Annu Rev Phytopathol 43, 205-227.

529 Hael-Conrad V, Abou-Mansour E, Diaz-Ricci JC, Metraux JP, Serrano M. 2015. The novel elicitor 530 AsES triggers a defense response against Botrytis cinerea in Arabidopsis thaliana. Plant Sci 241, 120531127.

532 Hassan MA, Rouf R, Tiralongo E, May TW, Tiralongo J. 2015. Mushroom lectins: specificity, 533 structure and bioactivity relevant to human disease. Int J Mol Sci 16, 7802-7838.

534 Heim C, Hertzberg H, Butschi A, Bleuler-Martinez S, Aebi M, Deplazes P, Ku $\square$ nzler M, Stefanic S.

535 2015. Inhibition of Haemonchus contortus larval development by fungal lectins. Parasit Vectors 8, 425.

536 Jaber K, Cuartero Diaz G, Haubruge E, Francis F. 2008. Investigation of carbohydrate binding 537 property of a fungal lectin from Xerocomus chrysenteron and potential use on Myzus persicae aphid.

538 Commun Agric Appl Biol Sci 73, 629-638.

539 Jones JD, Dangl JL. 2006. The plant immune system. Nature 444, 323-329.

$540 \quad$ Ju $\square$ rgensen K. 2001. Untersuchungen zum Assimilat- und Wassertransfer in der Interaktion zwischen 541 Arabidopsis thaliana and Heterodera schachtii. PhD thesis, Agrar- und Ernährungswissenschaftliche 542 Fakultät, Christian-Albrecht Universität, Kiel, Germany.

543 Karimi M, Inze D, Depicker A. 2002. GATEWAY vectors for Agrobacterium-mediated plant 544 transformation. Trends Plant Sci 7, 193-195.

545 Künzler M. 2015. Hitting the sweet spot-glycans as targets of fungal defense effector proteins. Molecules $54620,8144-8167$.

547 Künzler M. 2018. How fungi defend themselves against microbial competitors and animal predators. 548 Plos Pathogens 14, e1007184. 
Lindsey BE, 3rd, Rivero L, Calhoun CS, Grotewold E, Brkljacic J. 2017. Standardized method for high-throughput sterilization of Arabidopsis seeds. J Vis Exp, e56587.

Macho AP, Zipfel C. 2015. Targeting of plant pattern recognition receptor-triggered immunity by bacterial type-III secretion system effectors. Curr Opin Microbiol 23, 14-22.

Mauch-Mani B, Baccelli I, Luna E, Flors V. 2017. Defense priming: an adaptive part of induced resistance. Annu Rev Plant Biol 68, 485-512.

Mauch F, Mauch-Mani B, Gaille C, Kull B, Haas D, Reimmann C. 2001. Manipulation of salicylate content in Arabidopsis thaliana by the expression of an engineered bacterial salicylate synthase. Plant $\mathbf{J}$ 25, 67-77.

Oka Y, Cohen Y, Spiegel Y. 1999. Local and systemic induced resistance to the root-knot nematode in tomato by DL-beta-Amino-n-Butyric Acid. Phytopathol 89, 1138-1143.

Pieterse CM, Van der Does D, Zamioudis C, Leon-Reyes A, Van Wees SC. 2012. Hormonal modulation of plant immunity. Annu Rev Cell Dev Biol 28, 489-521.

Rao X, Huang X, Zhou Z, Lin X. 2013. An improvement of the $2^{\wedge}$ (-delta delta CT) method for quantitative real-time polymerase chain reaction data analysis. Biostat Bioinforma Biomath 3, 71-85.

Ripoll C, Favery B, Lecomte P, Van Damme E, Peumans W, Abad P, Jouanin L. 2003. Evaluation of the ability of lectin from snowdrop (Galanthus nivalis) to protect plants against root-knot nematodes. Plant Sci 164, 517-523.

Robert-Seilaniantz A, Grant M, Jones JD. 2011. Hormone crosstalk in plant disease and defense: more than just jasmonate-salicylate antagonism. Annu Rev Phytopathol 49, 317-343.

Ross A, Somssich IE. 2016. A DNA-based real-time PCR assay for robust growth quantification of the bacterial pathogen Pseudomonas syringae on Arabidopsis thaliana. Plant Methods 12, 48.

Sabotic J, Ohm RA, Künzler M. 2016. Entomotoxic and nematotoxic lectins and protease inhibitors from fungal fruiting bodies. Appl Microbiol Biotechnol 100, 91-111.

Sanchez-Vallet A, Ramos B, Bednarek P, Lopez G, Pislewska-Bednarek M, Schulze-Lefert P, Molina A. 2010. Tryptophan-derived secondary metabolites in Arabidopsis thaliana confer non-host resistance to necrotrophic Plectosphaerella cucumerina fungi. Plant J 63, 115-127.

Schubert M, Bleuler-Martinez S, Butschi A, Walti MA, Egloff P, Stutz K, Yan S, Collot M, Mallet JM, Wilson IB, Hengartner MO, Aebi M, Allain FH, Künzler M. 2012. Plasticity of the beta-trefoil protein fold in the recognition and control of invertebrate predators and parasites by a fungal defence system. Plos Pathogens 8, e1002706.

Schütze K, Harter K, Chaban C. 2009. Bimolecular fluorescence complementation (BiFC) to study protein-protein interactions in living plant cells. Methods Mol Biol 479, 189-202.

Schwessinger B, Zipfel C. 2008. News from the frontline: recent insights into PAMP-triggered immunity in plants. Curr Opin Plant Biol 11, 389-395. 
584 Sharon N, Lis H. 2004. History of lectins: from hemagglutinins to biological recognition molecules.

585 Glycobiology 14, 53-62.

586 Sijmons PC, Grundler FMW, von Mende N, Burrows PR, Wyss U. 1991. Arabidopsis thaliana as a 587 new model host for plant-parasitic nematodes. Plant J 1, 245-254.

588 Singh RS, Kaur HP, Singh J. 2014. Purification and characterization of a mucin specific mycelial lectin

589 from Aspergillus gorakhpurensis: application for mitogenic and antimicrobial activity. PLoS One 9, $590 \mathrm{e} 109265$.

591 Singh RS, Walia AK, Kennedy JF. 2019. Mushroom lectins in biomedical research and development.

592 Int J Biol Macromol 151, 1340-1350.

593 Stefanowicz K, Lannoo N, Proost P, Van Damme EJ. 2012. Arabidopsis F-box protein containing a 594 Nictaba-related lectin domain interacts with N-acetyllactosamine structures. FEBS Open Bio 2, 151-158.

595 Stefanowicz K, Lannoo N, Zhao Y, Eggermont L, Van Hove J, Al Atalah B, Van Damme EJ. 2016.

596 Glycan-binding F-box protein from Arabidopsis thaliana protects plants from Pseudomonas syringae 597 infection. BMC Plant Biol 16, 213.

598 Stutz K, Kaech A, Aebi M, Künzler M, Hengartner MO. 2015. Disruption of the C. elegans intestinal 599 brush border by the fungal lectin CCL2 phenocopies dietary lectin toxicity in mammals. PLoS One 10, $600 \mathrm{e} 0129381$.

601 Tayyrov A, Schmieder SS, Bleuler-Martinez S, Plaza DF, Künzler M. 2018. Toxicity of potential

602 fungal defense proteins towards the fungivorous nematodes Aphelenchus avenae and Bursaphelenchus 603 okinawaensis. Appl Environ Microbiol 84, e02051-02018.

604 Trigueros V, Lougarre A, Ali-Ahmed D, Rahbe Y, Guillot J, Chavant L, Fournier D, Paquereau L.

605 2003. Xerocomus chrysenteron lectin: identification of a new pesticidal protein. Biochim Bioph Acta 606 1621, 292-298.

607 Tripathi D, Raikhy G, Kumar D. 2019. Chemical elicitors of systemic acquired resistance-salicylic 608 acid and its functional analogs. Curr plant biol 17, 48-59.

609 Van Damme EJ, Barre A, Rouge P, Peumans WJ. 2004. Cytoplasmic/nuclear plant lectins: a new 610 story. Trends Plant Sci 9, 484-489.

611 Van Holle S, Smagghe G, Van Damme EJ. 2016. Overexpression of Nictaba-Like lectin genes from 612 Glycine max confers tolerance toward Pseudomonas syringae infection, aphid infestation and salt stress 613 in transgenic Arabidopsis plants. Front Plant Sci 7, 1590.

614 Van Holle S, Van Damme EJM. 2018. Signaling through plant lectins: modulation of plant immunity 615 and beyond. Biochem Soc Trans 46, 217-233.

616 Vandenborre G, Smagghe G, Van Damme EJ. 2011. Plant lectins as defense proteins against 617 phytophagous insects. Phytochem 72, 1538-1550. 
618 Varrot A, Basheer SM, Imberty A. 2013. Fungal lectins: structure, function and potential applications. 619 Curr Opin Struct Biol 23, 678-685.

620 Wohlschlager T, Butschi A, Zurfluh K, Vonesch SC, auf dem Keller U, Gehrig P, Bleuler-Martinez

621 S, Hengartner MO, Aebi M, Künzler M. 2011. Nematotoxicity of Marasmius oreades agglutinin

622 (MOA) depends on glycolipid binding and cysteine protease activity. J Biol Chem 286, 30337-30343.

623 Yan Y, Yuan Q, Tang J, Huang J, Hsiang T, Wei Y, Zheng L. 2018. Colletotrichum higginsianum as a 624 model for understanding host-pathogen interactions: A Review. Int J Mol Sci 19.

625 Zhang L, Paasch BC, Chen J, Day B, He SY. 2019. An important role of 1-fucose biosynthesis and 626 protein fucosylation genes in Arabidopsis immunity. New Phytol 222, 981-994.

627 Zhang X, Henriques R, Lin SS, Niu QW, Chua NH. 2006. Agrobacterium-mediated transformation of 628 Arabidopsis thaliana using the floral dip method. Nature Protocols 1, 641-646. 


\section{Figure Legends}

631

632

633

634

635

636

637

638

639

640

641

642

643

644

645

646

647

648

649

650

651

652

653

654

655

656

657

658

659

660

661

662

Fig. 1. Characterization of CCL2-expressing Arabidopsis lines. (A) qPCR analysis of relative CCL2 and CCL2-Y92A transcript levels in four-week-old plants. Transcript levels were normalized to $\exp G$ gene (AT4G26410). Mean values \pm SE of 3 independent experiments. (B) Immunoblot visualizing the expression level of CCL2 and CCL2-Y92A proteins. FLAG-tagged proteins were detected with antiFLAG antibodies. Ponceau-S stained Rubisco large subunit served as loading control. (C) Growth phenotype of transgenic lines compared to WT. Two independent lines (L1 and L2) are shown for each construct. (D) Fresh weight (FW) and (E) dry weight (DW) of shoots of four-week-old plants (n=12; 3 independent experiments). Boxplots represent median and 1.5 times the interquartile range. Asterisks show significant differences between transgenic lines compared to the WT (***p $\leq 0.001, * * \mathrm{P} \leq 0.01$ ) determined by one-way ANOVA followed by post-hoc analysis with Dunnett's multiple-comparison test.

Fig. 2. Partial resistance of CCL2-expressing plants towards the cyst nematode $H$. schachtii. Twelve-dayold Arabidopsis seedlings (WT, CCL2 and CCL2-Y92A lines) were inoculated with 30 freshly hatched juveniles per plant and evaluated $14 \mathrm{dpi}$ for number of female nematodes per root centimeter. Boxplots represent median and 1.5 times the interquartile range (WT and CCL2 lines n= 16; CCL2-Y92A n=15; 3 independent experiments). Asterisks above columns indicate statistically significant differences (***p $\leq$ $0.001, * * \mathrm{P} \leq 0.01)$ between CCL2 lines and WT plants, analyzed by one-way ANOVA and post-hoc analysis with Dunnett's multiple-comparison test.

Fig. 3. Resistance of CCL2-expressing plants towards fungal pathogens. (A) Necrotic lesions caused by B. cinerea infection on leaves of four-week-old WT, CCL2- and CCL2-Y92A lines inoculated with $6 \mu \mathrm{L}$ droplets of a spore suspension $\left(5 \times 10^{4}\right.$ spores $\left.\mathrm{mL}^{-1}\right)$. Plants were photographed 3 dpi. Size bar=1cm. (B) Trypan Blue-staining of Arabidopsis leaves 60 hpi. The right-side shows close-up images. Black or red size bares are $1 \mathrm{~mm}$ and $50 \mu \mathrm{m}$, respectively. (C) Quantification of lesion size at 3 dpi. Boxplots represent median and 1.5 times the interquartile range $(n=80$ from three independent experiments). (D) Quantification of fungal DNA by qPCR at 0,1 , and 2 dpi. The fungal Cutinase A gene (Genebank: Z69264) was quantified relative to $\exp G$ gene (AT4G26410) of Arabidopsis. Bars represent mean values \pm SE from three independent experiments. (E) Analysis of lesion size of five-week-old WT and transgenic CCL2 lines droplet-inoculated with $C$. higginsianum $\left(10 \mu \mathrm{L}\right.$ of $2 \times 10^{6}$ spores $\mathrm{mL}^{-1}$ per leaf). Plants were analyzed 10 dpi. (F) Analysis of lesion size of four-week-old WT and CCL2 lines, droplet-inoculated with $P$. cucumerina $\left(10 \mu \mathrm{L}\right.$ of $5 \times 10^{6}$ spores $\mathrm{mL}^{-1}$ per leaf). Plants were analyzed 5 dpi. Boxplots (E, F) represent median and 1.5 times the interquartile range $(n=30$ from three independent experiments). The 
data was analyzed by one-way ANOVA and post-hoc analysis by Dunnett's multiple-comparison test. Asterisks show a statistically significant difference between the CCL2 expressing lines and WT plants $(* * * \mathrm{P} \leq 0.001, * * \mathrm{P} \leq 0.01 ; * \mathrm{P} \leq 0.05$, ns, not significant). The letters a and $\mathrm{b}$ signify a between-group difference at the $\mathrm{P} \leq 0.05$ level.

Fig. 4. CCL2 enhances induction of Arabidopsis defense gene expression in response to B. cinerea. Fourweek-old Arabidopsis plants (WT, CCL2 and CCL2-Y92A lines) were spray-inoculated with B. cinerea $\left(5 \times 10^{5}\right.$ spores $\left.\mathrm{mL}^{-1}\right)$. Leaves were harvested at 0 and 1 dpi for RNA extraction. Transcript levels of $O B P 2$ (A), PDF1.2 (B), and PR-1 (C) were determined by qPCR. Data were normalized with regard to the Arabidopsis reference gene $\exp G$. Data represent mean values \pm SE of 3 independent experiments. The letters a and b signify a between-group difference at the $\mathrm{P} \leq 0.05$ level. Two-way ANOVA and post-hoc analysis by Tukey's multiple-comparison test were used to calculate significant differences between TG lines and WT plants.

Fig. 5. Increased resistance of CCL2-lines towards the bacterial pathogen $P$. syringae. Growth of virulent Pst DC3000 in WT plants and CCL2 lines was analyzed at 3 dpi. The bacterial $O p r F$ gene was quantified by qPCR using DNA extracted from inoculated leaves. Ten leaf discs from 6 plants were sampled per replicate. The plant $\exp G$ gene served as reference. Data represent mean values $\pm \mathrm{SE}$ of 3 independent experiments $(\mathrm{n}=18)$. Asterisks indicate statistically significant differences ( $* \mathrm{P} \leq 0.05$, $* * \mathrm{P} \leq 0.01$, ns: not significant; one-way ANOVA and post-hoc analysis with Dunnett's multiple-comparison test) between transgenic lines and wild type.

Fig. 6. Exogenous application of purified CCL2 induces defense gene expression and SAR towards $P$. syringae. Three leaves of four-week-old wild type plants were infiltrated with $10 \mathrm{mM} \mathrm{MgCl} 2$ (negative mock control), Pst DC3000 $\left(10^{6} \mathrm{CFU} \mathrm{mL}{ }^{-1}\right)$ as positive SAR control, or $500 \mu \mathrm{g} \mathrm{mL}^{-1}$ of purified CCL2 or CCL2-Y92A protein, respectively. (A) Forty-eight hours post treatment, three distal leaves were challenge-inoculated with Pst DC3000 $\left(10^{5} \mathrm{CFU} \mathrm{mL}^{-1}\right)$. Ten leaf discs per treatment were sampled from distal leaves of 10 plants at 3 dpi to quantify by qPCR the abundance of the bacterial $O p r F$ gene as a proxy for bacterial biomass. (B-F) Transcript levels relative to $\exp G$ gene in local leaves 48 hours after treatment (B) GLI1 (AT1G80460), (C) GLY1 (AT2G40690), (D) PR-1 (AT2G14610), (E) RBOHD (AT5G47910), and (F) RBOHF (AT1G64060). Asterisks indicate statistically significant differences (*P $\leq 0.05, * * \mathrm{P} \leq 0.01$, ns: not significant; one-way ANOVA and post-hoc analysis with Dunnett's multiple- 
bioRxiv preprint doi: https://doi.org/10.1101/2021.01.12.426396; this version posted January 12, 2021. The copyright holder for this preprint (which was not certified by peer review) is the author/funder, who has granted bioRxiv a license to display the preprint in perpetuity. It is made available under aCC-BY-NC-ND 4.0 International license.

695 comparison test) between treatments and mock control. Data represent mean \pm SD of 3 biological 696 replicates. 
A

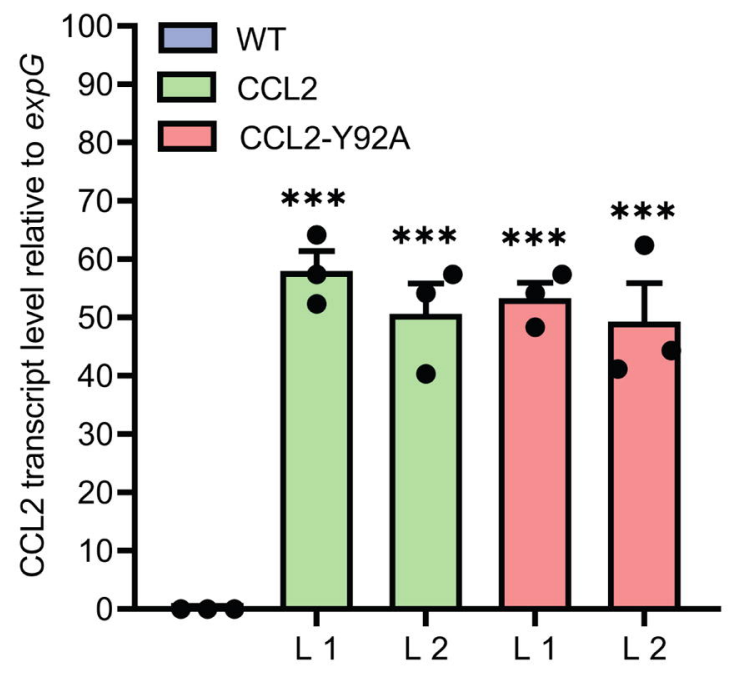

B

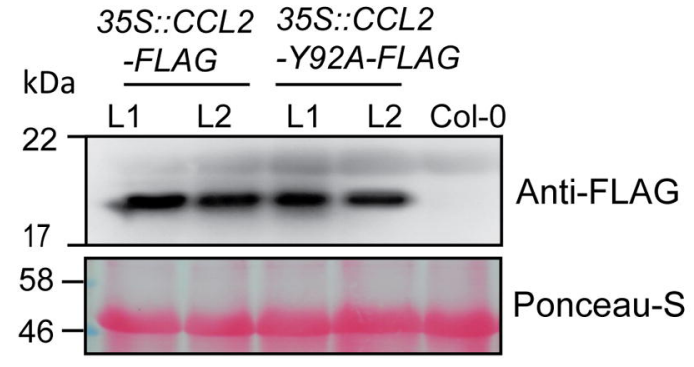

D

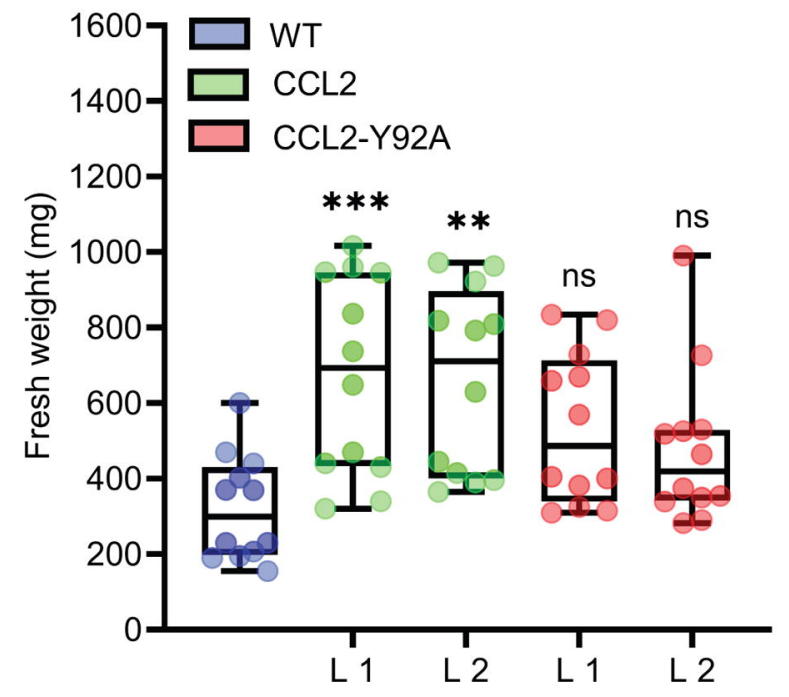

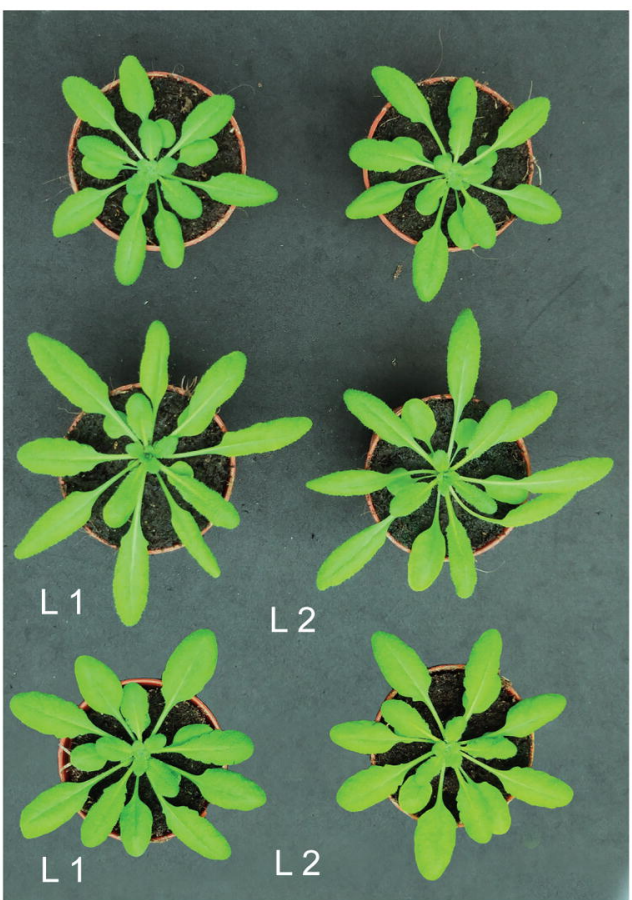
CCL2-
Y92A

CCL2

E

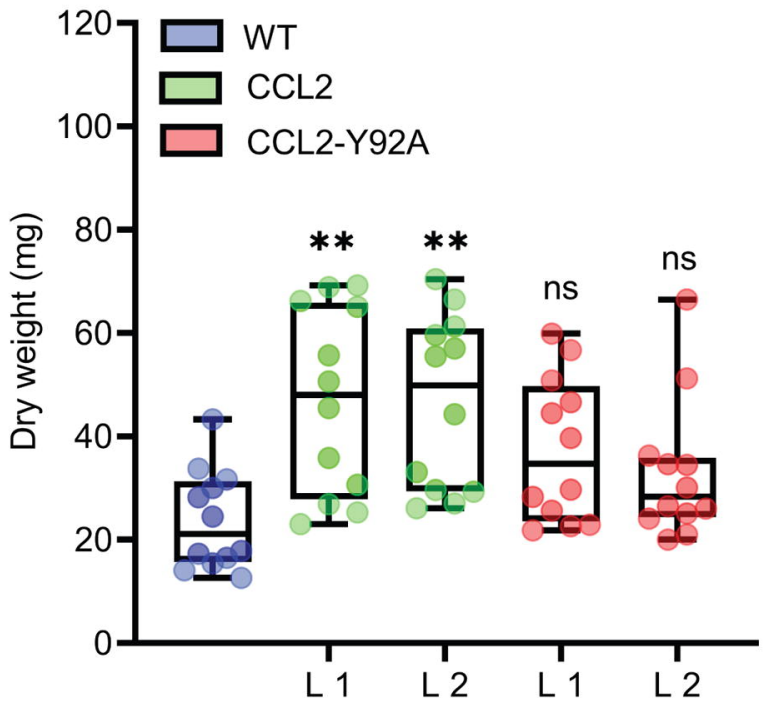




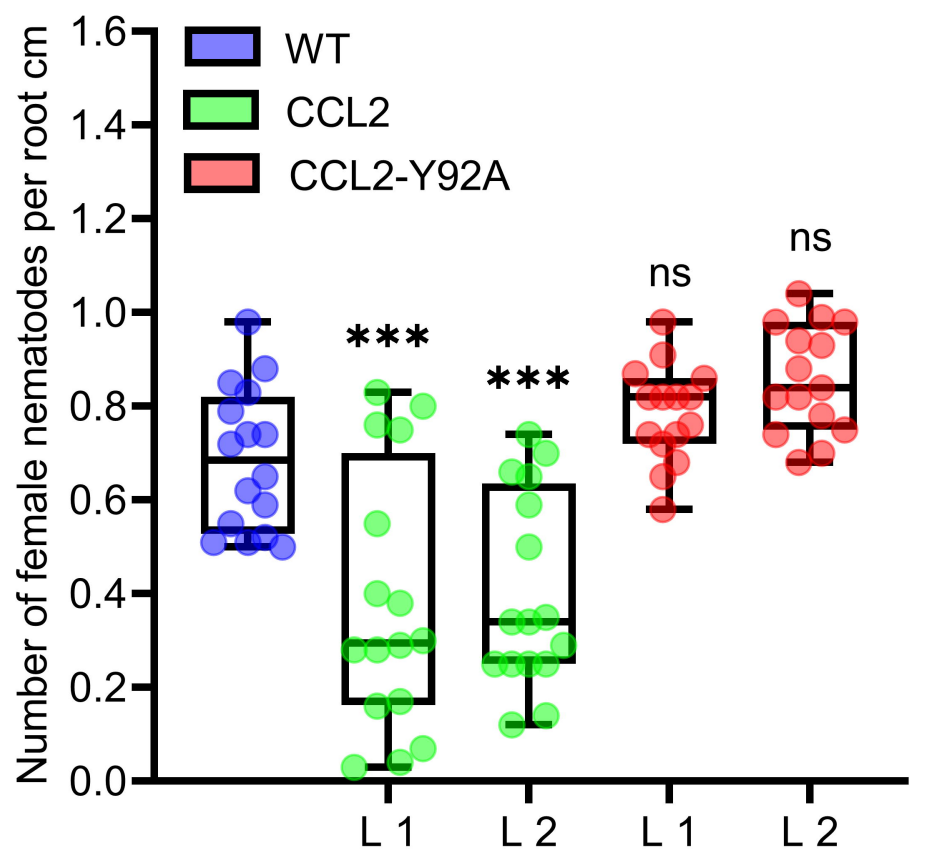




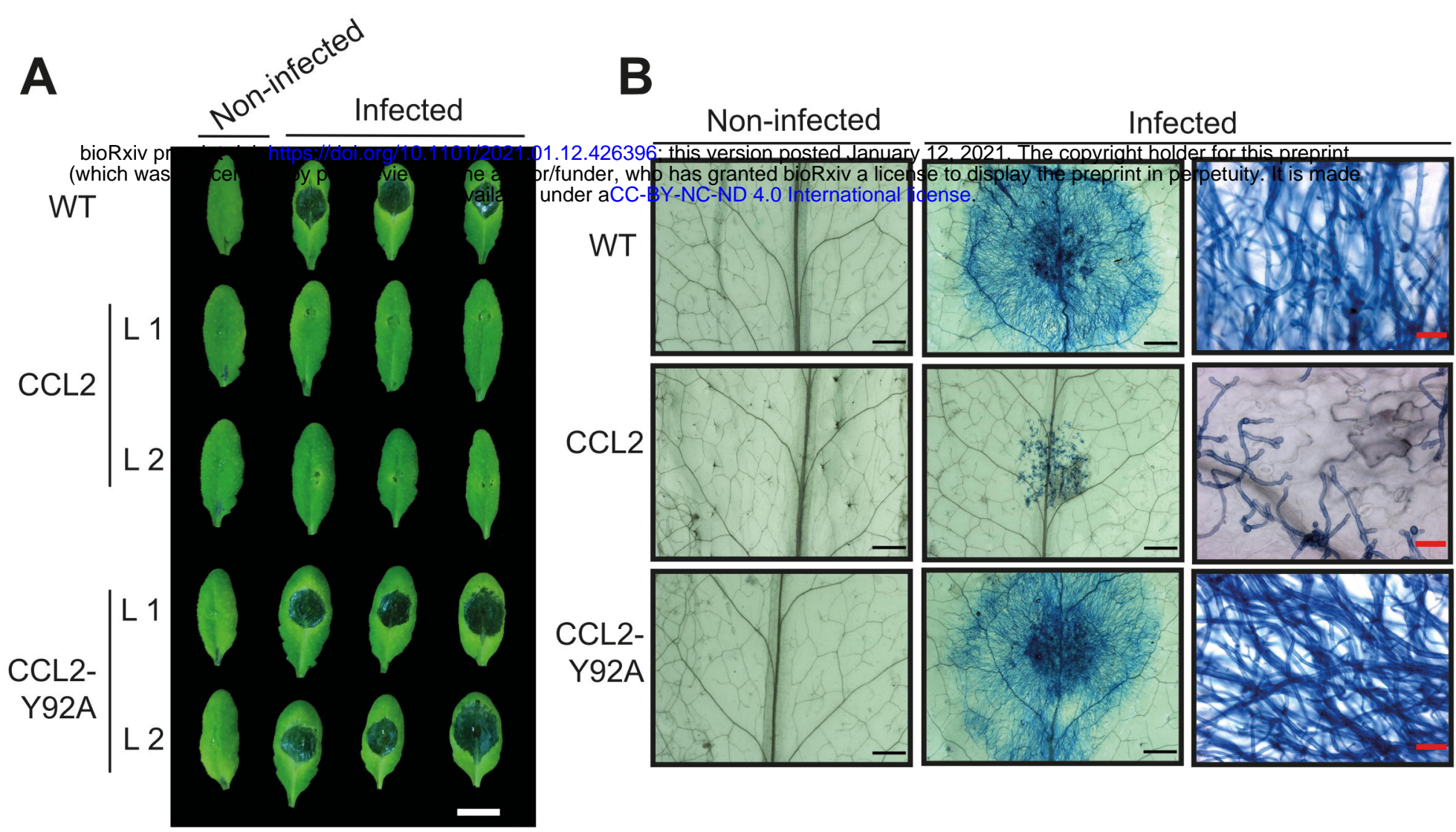

C

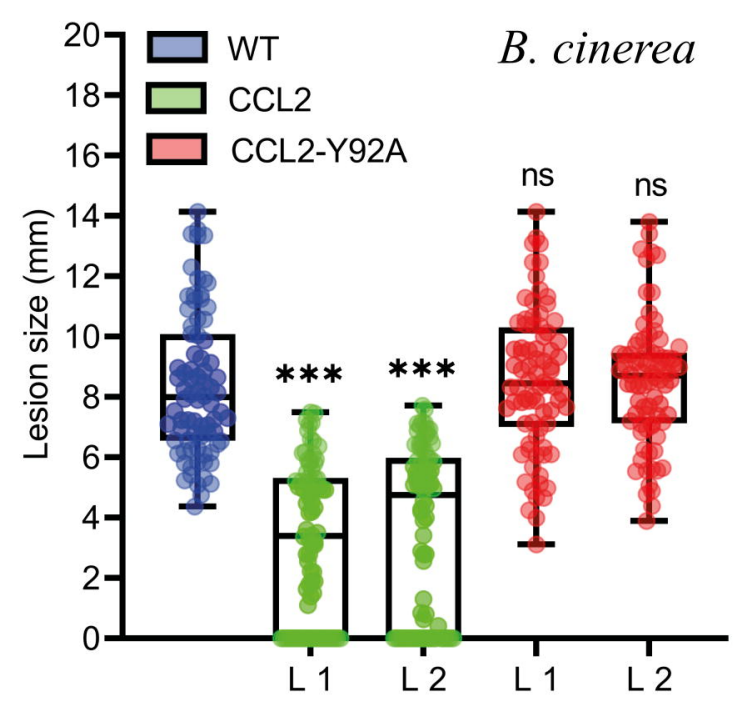

E

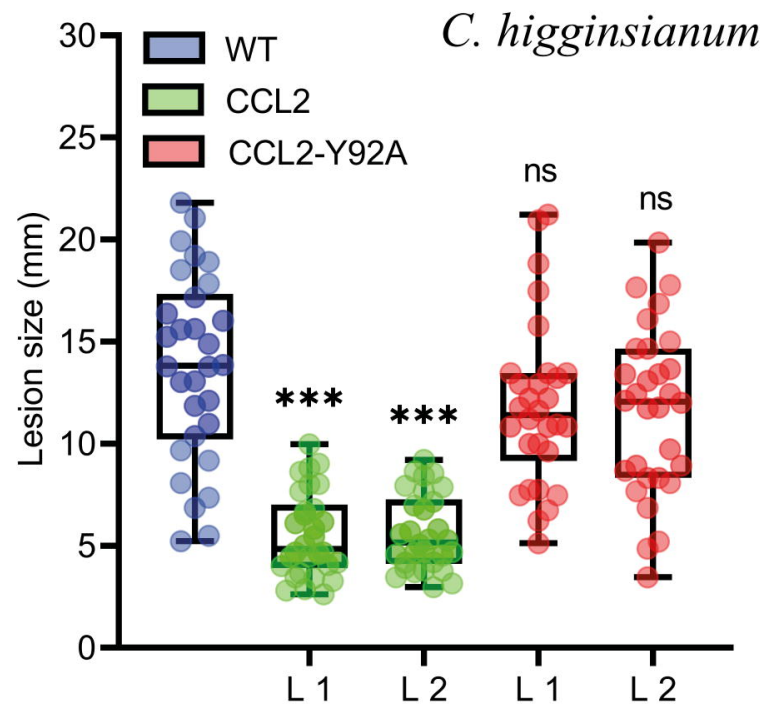

D

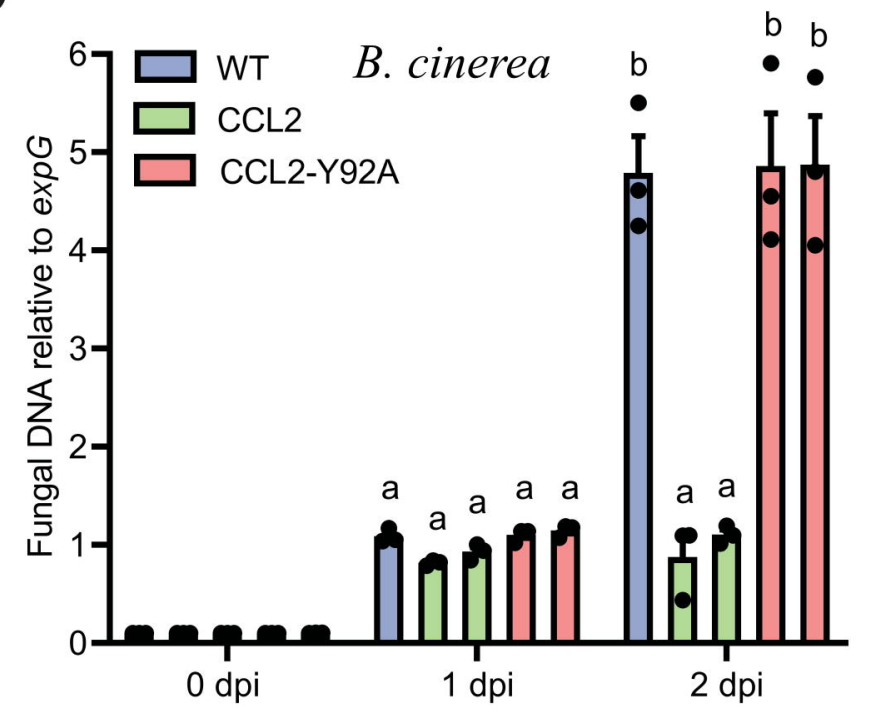

두

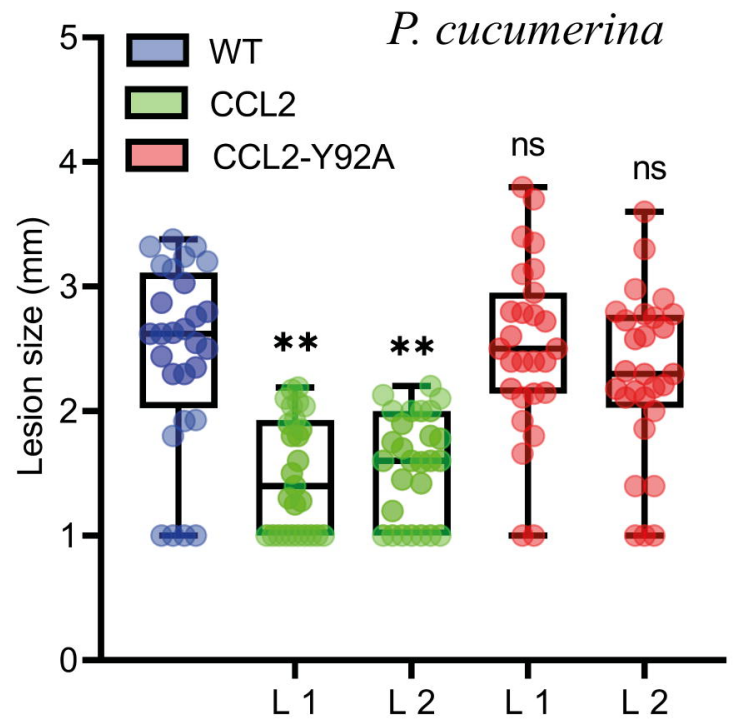


A

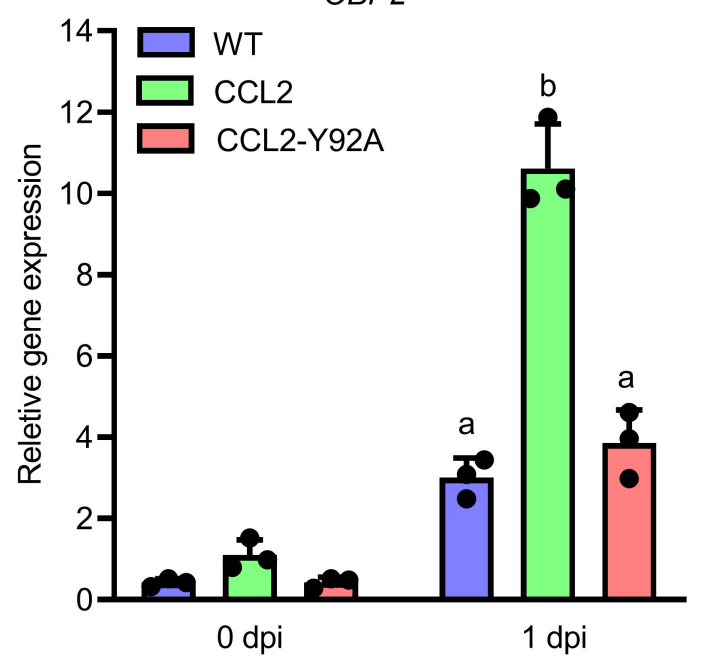

B

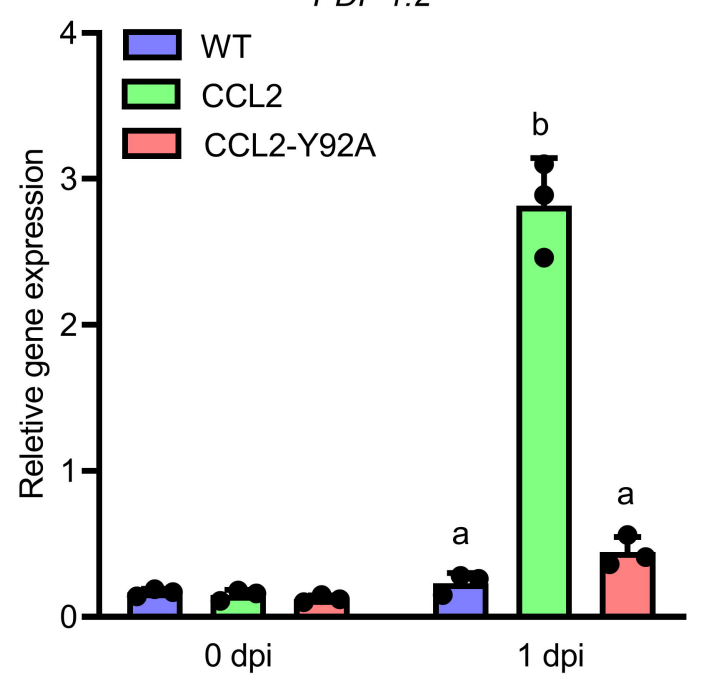

C

PR-1

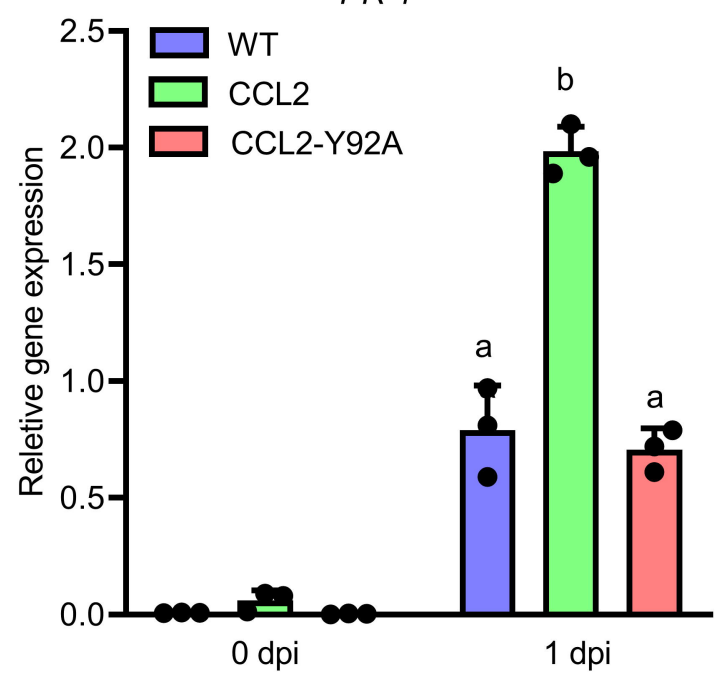




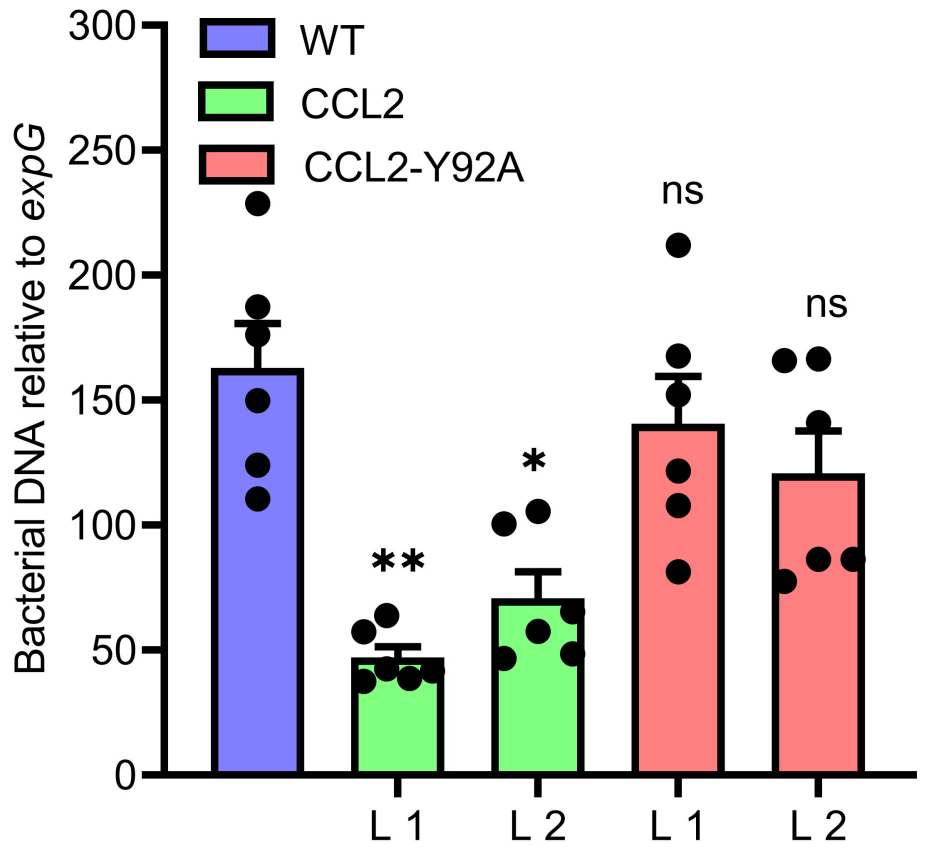


A
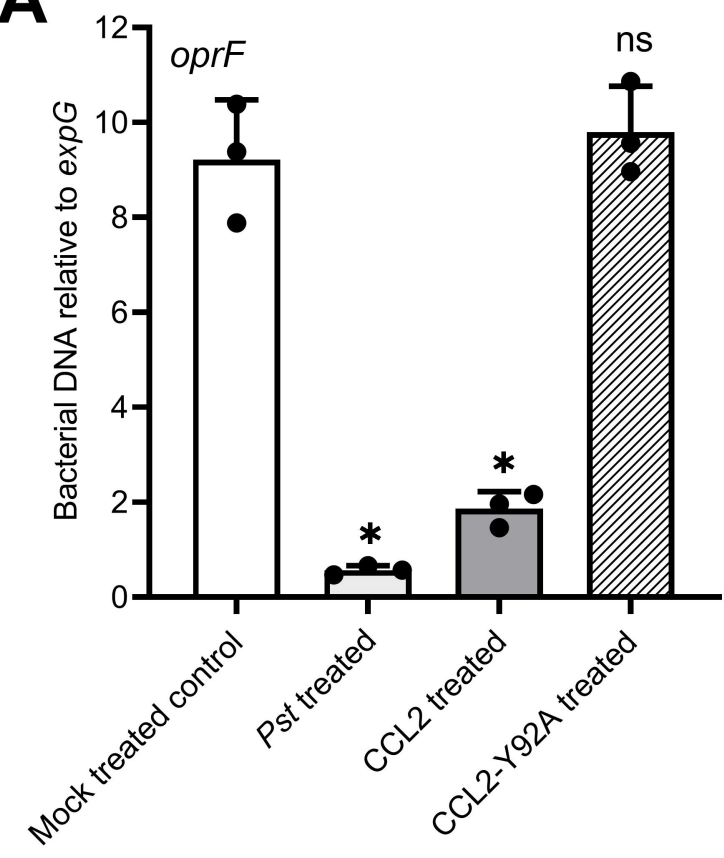

D

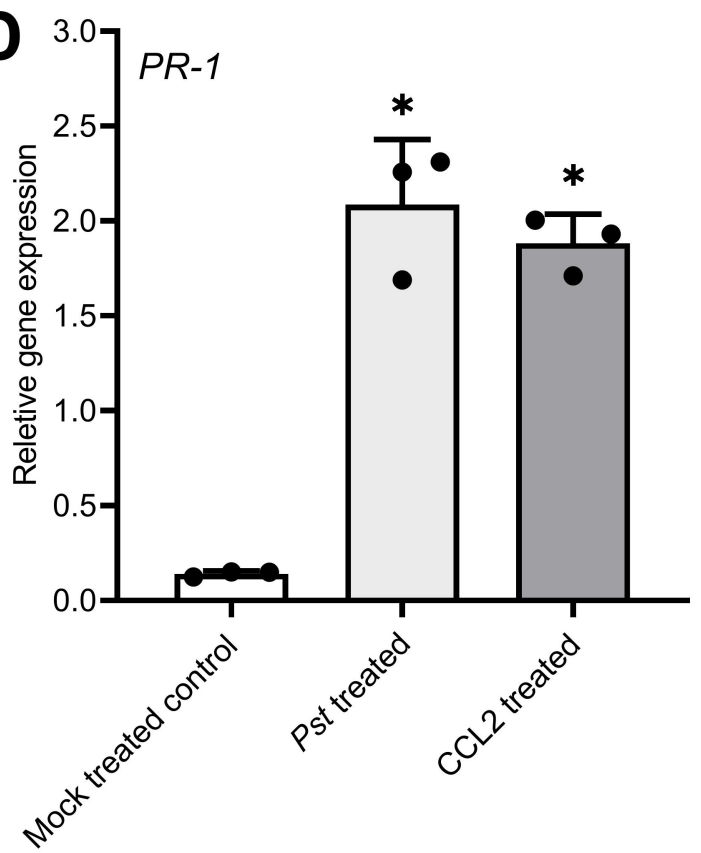

B

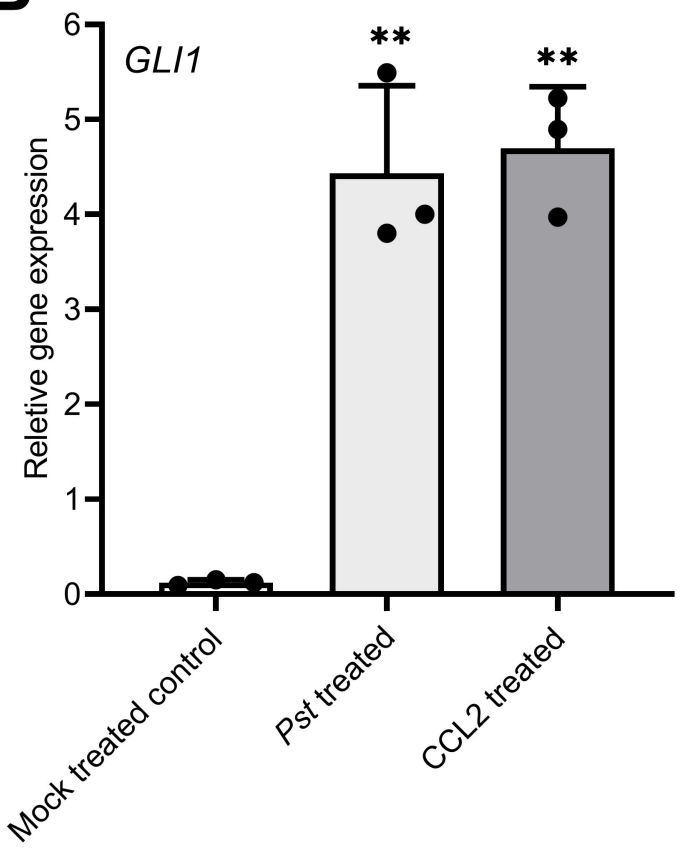

E

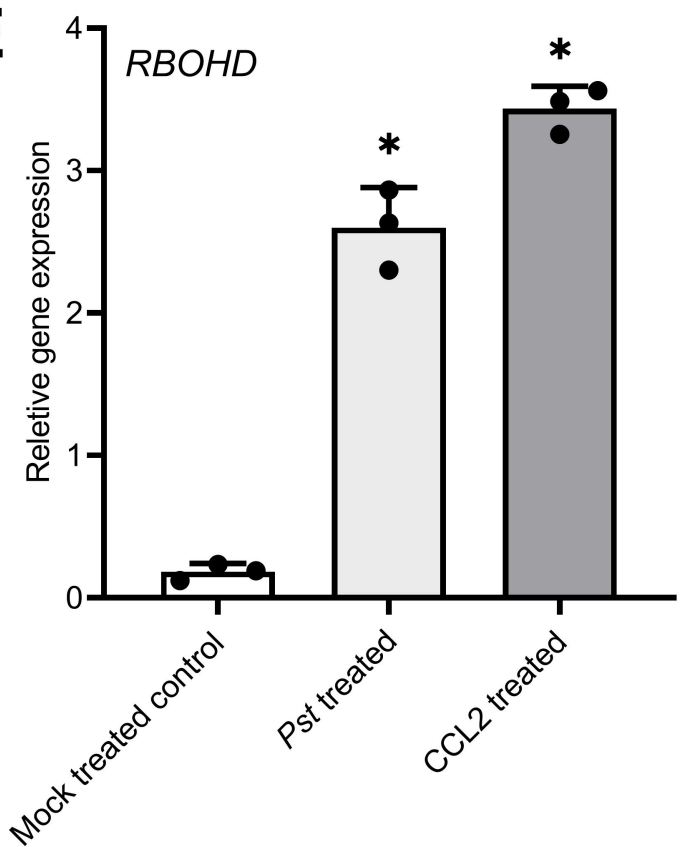

C
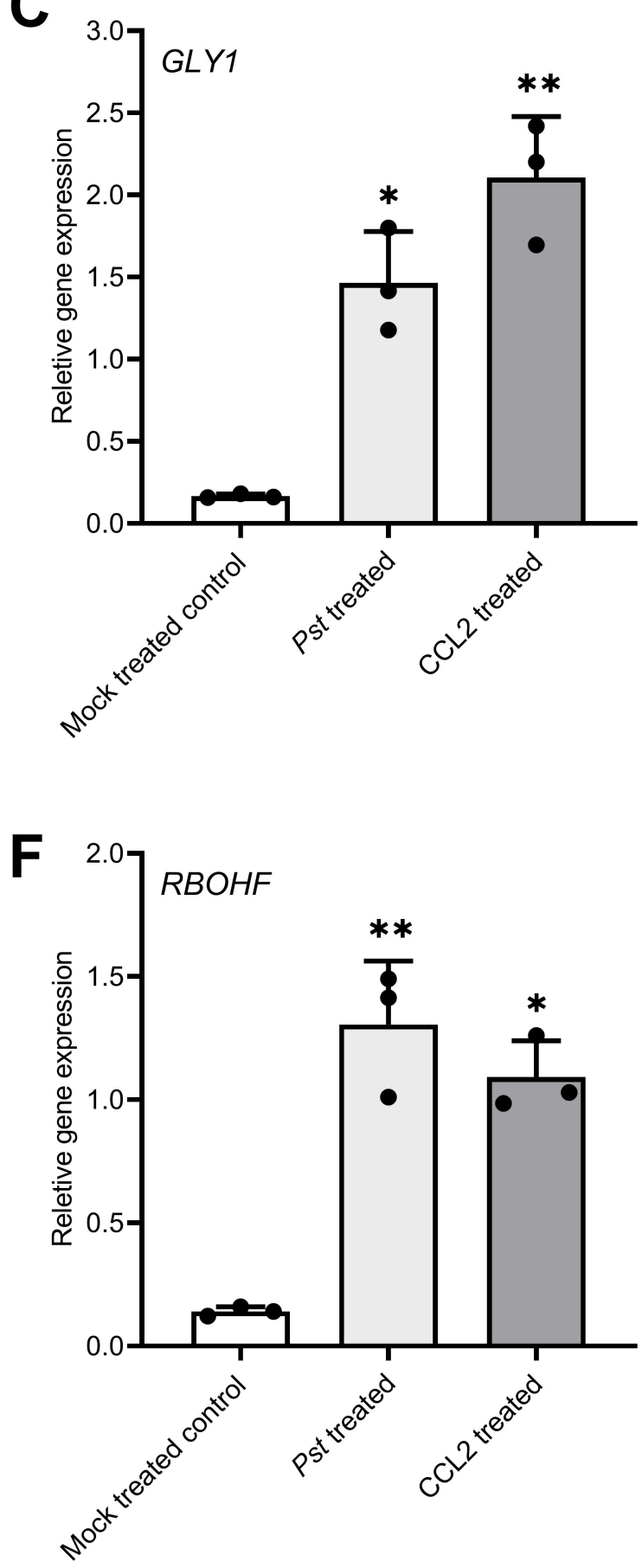